NBER WORKING PAPER SERIES

\title{
SORTING IT OUT: INTERNATIONAL TRADE AND PROTECTION WITH HETEROGENEOUS WORKERS
}

\author{
Franziska Ohnsorge \\ Daniel Trefler \\ Working Paper 10959 \\ http://www.nber.org/papers/w10959
NATIONAL BUREAU OF ECONOMIC RESEARCH
1050 Massachusetts Avenue
Cambridge, MA 02138
December 2004

We are indebted to Daron Acemoglu, George Bound, Alan Deardorff, Gordon Hanson, Elhanan Helpman, Jim Levinsohn, Diego Puga, Alysios Siow, Nadia Soboleva, and Alwyn Young for constructive comments. Derek Neal was kind enough to pull a confused Trefler aside after an Applications Workshop and initiate him into the wonderful world of Roy. We are particularly grateful to Jim Heckman and Sherwin Rosen for their encouragement, guidance, and patience. Funding for this project has been generously provided by the Social Sciences and Humanities Research Council (SSHRC) of Canada. The views expressed herein are those of the author(s) and do not necessarily reflect the views of the National Bureau of Economic Research.

(C) 2004 by Franziska Ohnsorge and Daniel Trefler. All rights reserved. Short sections of text, not to exceed two paragraphs, may be quoted without explicit permission provided that full credit, including $(\odot)$ notice, is given to the source. 
Sorting It Out: International Trade and Protection With Heterogeneous Workers

Franziska Ohnsorge and Daniel Trefler

NBER Working Paper No. 10959

December 2004

JEL No. F11, F13, F16, J3

\begin{abstract}
$\underline{\text { ABSTRACT }}$
The two models of international trade with developed factor markets -- Heckscher-Ohlin and Specific Factors -- both suffer significant defects. For example, their predictions about the patterns of domestic production and international trade are for the most part either indeterminate or uselessly complex. The problem with these models is that the supply of factors to an industry is either perfectly elastic or perfectly inelastic. Using a model in which heterogeneous workers sort across industries we eliminate this problem. The result is a multi-good model with sharp predictions about (1) the domestic pattern of production, (2) North-North and North-South trade, (3) the demand for protection, (4) the determinants of domestic income distribution, and (5) the effect of trade on economic development.

Franziska Ohnsorge

International Monetary Fund

$70019^{\text {th }}$ Street, NW

Washington, DC 20431

fohnsorge@imf.org

Daniel Trefler

Rotmand School of Management and Department of Economics

University of Toronto

105 St. George Street

Toronto, Ontario M5S 3E6 CANADA

and NBER

dtrefler@rotman.utoronto.ca
\end{abstract}




\section{Introduction}

The two models of international trade with developed factor markets - Heckscher-Ohlin and Specific Factors - both suffer significant defects. For example, their predictions about the patterns of domestic production and international trade are unsatisfying. Except in the case of two goods and two factors, Heckscher-Ohlin production and trade patterns are either indeterminate or uselessly complex. In the Specific Factors model, these patterns have little intuitive appeal (Jones and Neary, 1984, page 24). For another example, the Specific Factors model was developed in order to explain why industries rather than factors lobby for protection (Mayer, 1974; Mussa, 1974). Unfortunately, the explanation is driven entirely by the deus ex machina assumption of immobile factors. This raises questions about what economic process generates the cross-industry distribution of immobile factors and why the immobility itself is not explained by the theory (Leamer, 1980; Grossman, 1983).

We show that these problems stem from the extreme assumption that factors are either perfectly mobile across industries or perfectly immobile. To avoid this problem we model labour markets using the Heckman and Sedlacek (1985) variant of the Roy (1950, 1951) model which describes the sorting behaviour of heterogenous workers endowed with two attributes e.g., problem-solving and communication skills. ${ }^{1}$ Workers sort across industries based on Ricardian comparative advantage. Industries differ by skill requirements and each worker sorts into the industry that pays the most for her particular bundle of skills. As a result, each heterogeneous worker has a preference for a particular industry because the

\footnotetext{
${ }^{1}$ Leamer (1999), Grossman and Maggi (2000) and Grossman (2004) offer very interesting trade models featuring worker sorting, but the sorting and hence the predictions are very different from our own. This will become clear shortly.
} 
next best alternative industry pays discretely less. Further, heterogeneity of workers means that even within an industry some workers are less productive and hence less well paid than others. These least productive workers will be the first to switch out of the industry should firms in the industry lower wages. This makes each industry's partial equilibrium supply of labour slope upwards. Restated, unlike the Heckscher-Ohlin and Specific Factors models, factors are neither perfectly mobile nor perfectly immobile and the degree of mobility is generated endogenously.

This simple alternative to the Heckscher-Ohlin and Specific Factors models leads to five important results. First, we obtain a complete generalization of the Rybczynski and Heckscher-Ohlin theorems for the case of arbitrarily many industries. Partial mobility is the key to this remarkable result since it implies that industry supply functions are continuous and upward sloping. In contrast, in the Heckscher-Ohlin and Ricardian models industry supply is discontinuous and infinitely elastic where price equals average cost. In the Specific Factors model the artifice of exogenous specificity makes industry supply continuous and upward sloping, but this comes at a cost: the patterns of domestic production and international trade have little intuitive appeal. Further, the patterns depend heavily on the cross-industry distribution of specific factors, a distribution that is exogenous and for which little intuition is available.

Second, partial mobility leads to new predictions about the political economy of protection. A worker who is a very good fit with the industry is endogenously immobile and demands protection for her industry. A worker who is only a modestly good fit with the industry is endogenously more mobile and will support protection for all industries that 
intensively use her type. The tension between the 'long-run' Stolper-Samuelson prediction about factor-based lobbying and the 'short-run' specific factors prediction about industrybased lobbying is eliminated. Leamer (1980) and Grossman (1983) were the first to recognize and deal with this tension. However, our resolution improves considerably on this earlier research by eliminating the need for exogenous mobility costs.

Third, while the effects on trade of international differences in average endowments are well known, nothing is known about the effects of other moments of the distribution of worker types. For example, since average endowments per capita are similar across rich countries it is often argued that the distribution of endowments cannot explain NorthNorth trade. However, it is also often argued that differences between Japanese and U.S. workers influence production patterns and comparative advantage. For example, Japanese comparative advantage in goods involving long chains of production and requiring reliability is often ascribed to a more uniform distribution of such skills as effective communication in worker circles. We model this in terms of higher moments of the distribution of worker characteristics. The idea that higher moments matter was put forward by Grossman and Maggi (2000) and Grossman (2004). We extend their insights using a very different model of labour markets.

Fourth, our model easily handles international technology differences without requiring it. Countries that use older vintages of technology survive by skimming the cream, that is, by operating at a smaller level of output and employing only those few workers whose skills are almost a perfect match for older-vintage technologies. While almost perfect, these matches are less productive and less well paying than rich-country matches of workers to 
new-vintage technologies. This is an essential observation for development economics where the international coexistence of old and new technologies has long been highlighted (Pack, 1984).

Fifth, the predictions of the model do not require factor price equalization. Worker earnings can differ across countries and will differ within industries because of differences in worker skills. As a result, we are able to develop the rich predictions about inequality associated with the Roy model. We discuss within-group inequality and within-industry inequality and then investigate the impact of trade and skill-biased technical change on these inequality measures.

The model we will be presenting is most closely related to the international trade model of Leamer (1999). Leamer considers a model with sorting based on a single worker characteristic, namely effort. Effort complements capital which leads to worker sorting. Introducing a second worker characteristic, as we do, leads to additional and important predictions about production, trade, earnings and inequality.

Our work on North-North trade is strongly influenced by Grossman and Maggi (2000) and Grossman (2004) though the mechanisms are different. In Grossman and Maggi (2000) machines are produced in long chains of production involving many workers. The machine is reliable only if each worker's input is reliable. This 'supermodularity' means that in equilibrium each hired worker will have a minimum level of talent. In contrast, software output depends on the input of the most talented worker. This 'submodularity' means that one hired worker will be highly talented and the remaining workers untalented. The main prediction is that the country with the greater dispersion in worker talents will have 
a comparative advantage in software. In our model there is no teamwork between workers, but there is 'teamwork' between the two attributes that a worker brings to the workplace. This leads to our section 5 trade-and-dispersion result. In Grossman (2004), machinery requires teamwork and software does not. Teamwork is subject to costly monitoring and incomplete contracting, which encourages talented workers to sort into software. Trade leads the country with greater dispersion in talent to increase software production. This resolves the contracting problem for talented workers, thus raising inequality. In contrast, our section 5 inequality-and-dispersion result is driven by sorting rather than incomplete contracting.

Our research is also related to an excellent paper by Ruffin (1999) who uses Rosen's (1978) model of two-factor sorting to explain away the tension between the political economy predictions of the Heckscher-Ohlin and Specific Factors models. However, in his model worker heterogeneity is not enough to explain away the tension. His argument relies critically on allowing capital to be perfectly mobile across industries, something we will not need or want: worker heterogeneity even without any capital accomplishes the same end in a crystal clear way. This last point indicates that our work is related to Melitz (2003) who uses firm heterogeneity to generate an upward-sloping supply of firms into export markets.

The paper is organized as follows. Sections 2-3 set up the model. Sections 4-6 develop multi-good Rybczynski, Heckscher-Ohlin, and income distribution theorems for higher-order moments of the distribution of endowments. Sections 7-9 describe the implications of the model for political economy, international technology differences and domestic income inequality. 


\section{The Model}

Each worker brings two attributes to the workplace, $h$ and $l$. While human capital and brawn are obvious and familiar attributes, in describing trade among rich countries we also have in mind subtler attributes such as problem-solving abilities, communication skills, and team-work skills. A type $(h, l)$ worker employed in industry $i$ produces a task level of $t_{i}(h, l)$. Each worker chooses the industry that pays the most for her attributes. This leads to worker sorting based on the standard logic of Ricardian comparative advantage. ${ }^{2}$

An employer cannot unbundle a worker's attributes and thus cares only about $t_{i}(h, l)$. This 'bundling' assumption is the core assumption of a large class of Roy-like (1950; 1951) models. The particular formulation used here is due to Heckman and Sedlacek (1985). ${ }^{3}$

For simplicity we make two assumptions which together ensure that a worker's marginal product is $\log$-linear in $h$ and $l$. First, we assume that industry output $Y_{i}$ is the sum of the tasks performed by workers in the industry. Mathematically, if industry $i$ employs a set of workers whose attributes $(h, l)$ lie in a set $\Omega_{h} \times \Omega_{l}$ then output is

$$
Y_{i}=A_{i} \int_{\Omega_{h}} \int_{\Omega_{l}} t_{i}(h, l) f_{h l}(h, l) d l d h
$$

where $f_{h l}(h, l)$ is the measure or number of $(h, l)$ types in the economy and where $A_{i}$ is a Hicks-neutral technology parameter. The linearity of output in worker tasks is the standard

\footnotetext{
${ }^{2}$ The logic is usually stated as follows. With two industries and two workers types $(h, l)$ and $\left(h^{\prime}, l^{\prime}\right)$, $t_{1}(h, l) / t_{2}(h, l)>t_{1}\left(h^{\prime}, l^{\prime}\right) / t_{2}\left(h^{\prime}, l^{\prime}\right)$ implies that the $(h, l)$ type sorts into industry 1 and the $\left(h^{\prime}, l^{\prime}\right)$ type sorts into industry 2. This Ricardian sorting mechanism is fundamental to our model. We repeat it here only because it will be harder to see once more structure is added to the model.

${ }^{3}$ See also Rosen $(1972,1974,1981)$, Willis and Rosen (1979), Sattinger (1980), Heckman and Scheinkman (1987), Bartel and Sicherman (1999) and especially Rosen (1978) and Heckman and Honoré (1990).
} 
simplification in the sorting literature because it implies that a worker's marginal product is independent of the characteristics of other workers in the industry e.g., Heckman and Sedlacek (1985). Notice that we have no other inputs such as capital. These can be introduced but add no additional insights. Given equation (1), the log earnings of a type $(h, l)$ worker is

$$
w_{i}(h, l)=\ln q_{i}+\ln A_{i}+\ln t_{i}(h, l)
$$

where $q_{i}$ is the producer price.

Second, we assume that the task function is log-linear: $t_{i}(h, l) \equiv h^{\beta_{i}} l^{1-\beta_{i}}$. Without loss of generality, we rank industries such that $\beta_{i}$ is increasing in $i$. In this way, $i$ indexes the $h$-intensity of the industry. This is needed for Heckscher-Ohlin-style predictions. ${ }^{4}$

Under these two assumptions, equilibrium with sorting is easily characterized. To facilitate this, define

$$
L \equiv \ln l, \quad S \equiv \ln (h / l), \quad \text { and } \quad p_{i} \equiv \ln q_{i}+\ln A_{i} .
$$

\footnotetext{
${ }^{4}$ While the production function (1) and the task function $t_{i}$ are uncomfortably restrictive, they are more general than what has been used in the sorting literature. One can distinguish three types of sorting models based on the number of worker types and the number of industries.

1. In models with a continuum of industries, there is perfect sorting so that all workers in an industry are the same in key aspects e.g., Sattinger (1975) and Teulings (1995). This allows one to generalize the industry production function. However, the continuum-of-industries assumption is useless here because it is precisely the heterogeneity of workers within each industry that interests us.

2. In models with only 2 industries, one can always redefine or 'rotate' attributes so that only one factor is used in each industry e.g., Heckman and Honoré (1990) and Ruffin (1999). In our setting, this is equivalent to setting $\beta_{1}=0$ and $\beta_{2}=1$. Since we allow for $n>2$, such rotation is not possible and our approach is clearly more general.

3. In the remaining models $(2<n<\infty)$, either there is a finite number of worker types or a Leontief production assumption e.g., Rosen (1978). Again, our production function is more general than this and the generality is substantive.
} 
Then $\ln t_{i}=L+\beta_{i} S_{i}$ and the log earnings of a type $(S, L)$ worker employed in industry $i$ is given by

$$
w_{i}(S, L)=p_{i}+L+\beta_{i} S
$$

Sorting is illustrated in figure 1 which plots $w_{i}(S, L)-L=p_{i}+\beta_{i} S$ against $S$. The figure plots these earnings profiles for industries $i-1, i$, and $i+1$. A worker with an $S$ between $S_{i-1}$ and $S_{i}$ chooses industry $i . S_{i}$ satisfies $p_{i}+\beta_{i} S_{i}=p_{i+1}+\beta_{i+1} S_{i}$ i.e., worker type $\left(S_{i}, L\right)$ earns the same in industries $i$ and $i+1$. Thus, the sorting rule is

$$
\text { Choose } i \quad \Leftrightarrow \quad S_{i-1}<S<S_{i}
$$

where

$$
S_{i} \equiv \frac{p_{i}-p_{i+1}}{\beta_{i+1}-\beta_{i}}, \quad S_{0} \equiv-\infty, \quad \text { and } \quad S_{n} \equiv \infty
$$

As drawn in figure 1, the line for industry $i$ lies above the intersection of the lines for industries $i-1$ and $i+1$. This ensures that the $S_{i}$ are increasing in $i$, as we have implicitly assumed in equation (4). If this is not the case then no worker chooses industry $i$ and industry $i$ has no domestic employment. It is therefore convenient to let $i=1, \ldots, n$ index industries with positive domestic employment. Then the $S_{i}$ are increasing in $i$.

Figure 1 highlights a key feature of the model. Suppose firms in industry $i$ offer slightly higher earnings so that the $w_{i}(S, L)-L$ profile shifts up. Then industry $i$ firms will attract slightly more workers (those with $S$ near either $S_{i-1}$ or $S_{i}$ ). That is, the partial equilibrium supply of workers to the industry is upward sloping. This differs from the Heckscher-Ohlin and Specific Factors models. In the former, a slight rise in industry wages attracts an infinite 


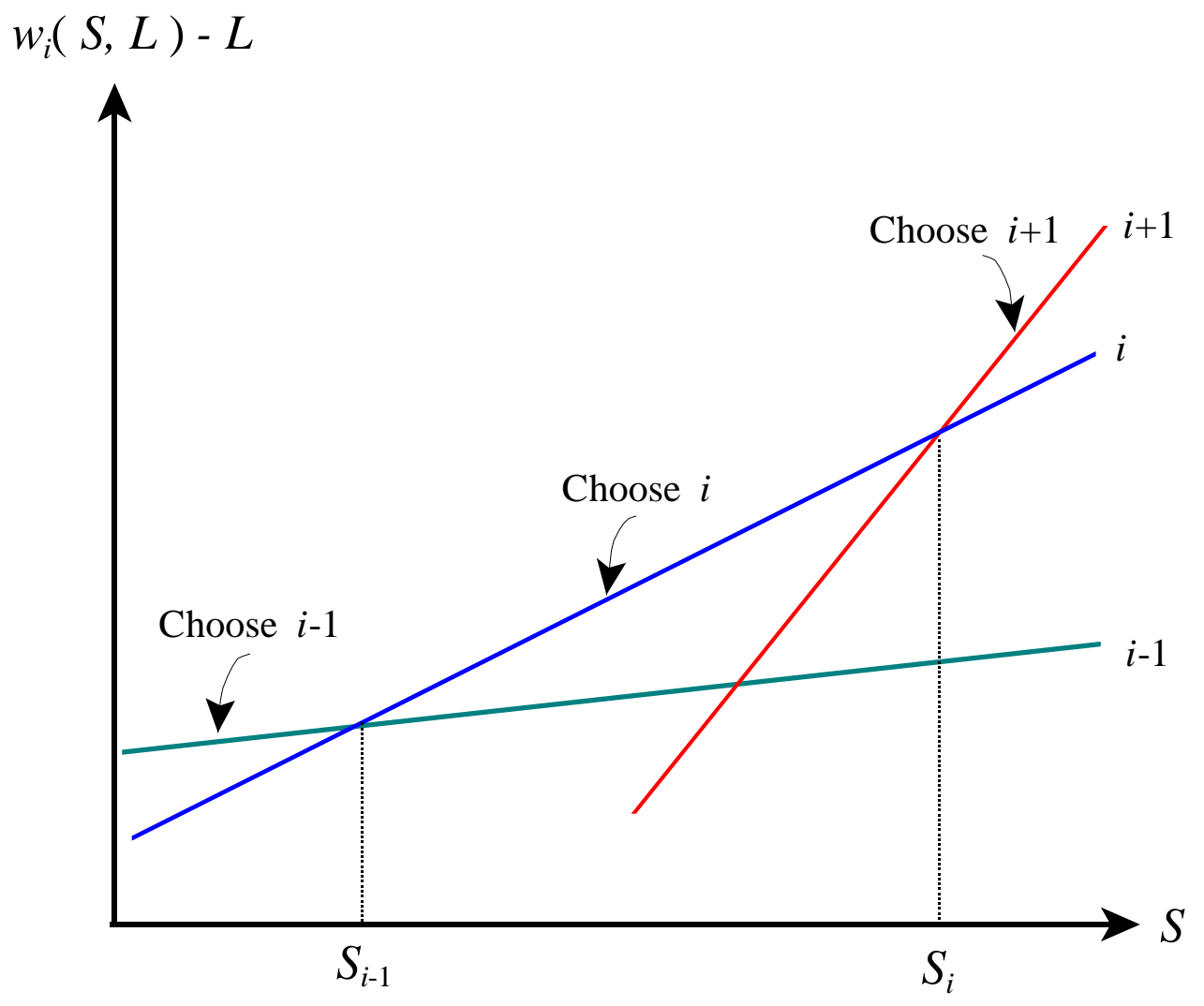

Figure 1: Worker Sorting.

supply of workers. In the latter, a slight rise in industry wages attracts either an infinite supply or no additional supply depending on whether labour is the mobile or immobile factor. Our model lies in between these extremes.

Note also that an upward-sloping supply of workers will imply an upward-sloping industry supply function. This does not appear in the Heckscher-Ohlin model (except via general equilibrium feedbacks) and appears in the Specific Factors model only through the deus ex machina of an exogenous fixed factor. ${ }^{5}$

\footnotetext{
${ }^{5}$ The fact that an employer cannot unbundle a worker's attributes and thus cares only about $t_{i}(h, l)$ is important for generating an upward-sloping supply of workers. Indeed, bundling is a standard sortingliterature device for inducing upward-sloping supplies. Further, upward-sloping supplies are often taken as evidence in favour of the bundling hypothesis. More formal evidence from structural econometric models
} 
With the sorting rule in place it is useful to fill in the details of the equation (1) expression for output $Y_{i}$. From equation $(2), t_{i}=h^{\beta_{i}} l^{1-\beta_{i}}=(h / l)^{\beta_{i}} l=\exp \left(\beta_{i} S+L\right)$. Let $f_{S L}(S, L)$ be the measure or number of type $(S, L)$ workers in the economy. ${ }^{6}$ Then

$$
Y_{i}=A_{i} \int_{S_{i-1}}^{S_{i}} \int_{-\infty}^{\infty} \exp \left(\beta_{i} S+L\right) f_{S L}(S, L) d L d S
$$

Turning to the definition of equilibrium, labour market equilibrium is described by a set of earnings functions $w_{i}(S, L), i=1, \ldots, n$ that satisfy profit-maximizing demand for tasks (equation 3) and earnings-maximizing supply of tasks (equation 4). Product markets are perfectly competitive and equilibrium in product markets is described by a set of producer prices $q_{1}, \ldots q_{n}$. We will sometimes discuss the determination of the $q_{i}$, especially when comparing autarky with free trade. At other times we will take the $q_{i}$ to be exogenous. This is in keeping with a small open economy facing exogenous world product prices and trade costs.

For some of the results of this paper we will need to make an assumption about $f_{S L}(S, L)$. Since there are no scale effects in the economy we take $f_{S L}$ to be a density function i.e., a positive function that integrates to unity. We follow the time-honoured tradition in the Roy

can be found in Willis and Rosen (1979), Heckman and Sedlacek (1985), Heckman and Scheinkman (1987), and Bartel and Sicherman (1999).

If workers can unbundle their $h$ and $l$ and take them to different industries then we are in a HeckscherOhlin world. If they must take their $h$ and $l$ to the same industry, but firms can unbundle workers' $h$ and $l$ (i.e., the firm only cares about the aggregate amounts of $h$ and $l$ that are hired) then we are almost in a Heckscher-Ohlin world, though now both countries and firms must be in the factor price equalization set. This point is developed in a debate between Welch (1969) and Rosen (1983).

${ }^{6} f_{S L}(S, L)$ is induced trivially by $f_{h l}(h, l)$ together with equation $(2)$. 
literature of assuming that $S$ and $L$ are bivariate normal:

$$
\left[\begin{array}{l}
S \\
L
\end{array}\right] \sim N\left(\left[\begin{array}{l}
\mu \\
0
\end{array}\right],\left[\begin{array}{cc}
\sigma^{2} & \rho \sigma \sigma_{L} \\
\rho \sigma \sigma_{L} & \sigma_{L}^{2}
\end{array}\right]\right)
$$

$\rho$ is the correlation between $S$ and $L . \sigma$ and $\sigma_{L}$ are not particularly interesting parameters so that we almost always set them to unity. All results in this paper hold for the general case of $\sigma \neq 1$ and $\sigma_{L} \neq 1$. This is explicitly shown in the appendix proofs where we do not restrict $\sigma$ or $\sigma_{L}$. Appendix $\mathrm{C}$ gives an expression for output under the assumption of normality.

\section{The Role of Two Attributes: Income Distribution}

The obvious thing about figure 1 is that workers are sorting based on the single attribute $S$ just as in Leamer (1999). What then is the role of two attributes? It turns out that both attributes are needed to discuss production, earnings, and earnings inequality. In particular, $\rho$ is crucial. To see this recall that under normality the expectation of $L$ given $S$ is

$$
\mathbf{E}(L \mid S)=\rho(S-\mu)
$$

From this and equation (3), the average log wages of type $S$ workers who have sorted into industry $i$ is

$$
\mathbf{E}\left(w_{i}(S, L) \mid S\right)=p_{i}-\rho \mu+\left(\beta_{i}+\rho\right) S
$$

The top panel of figure 2 plots $\mathbf{E}(L \mid S)$ against $S$ and plots a contour line for $f_{S L}(S, L)$ for 

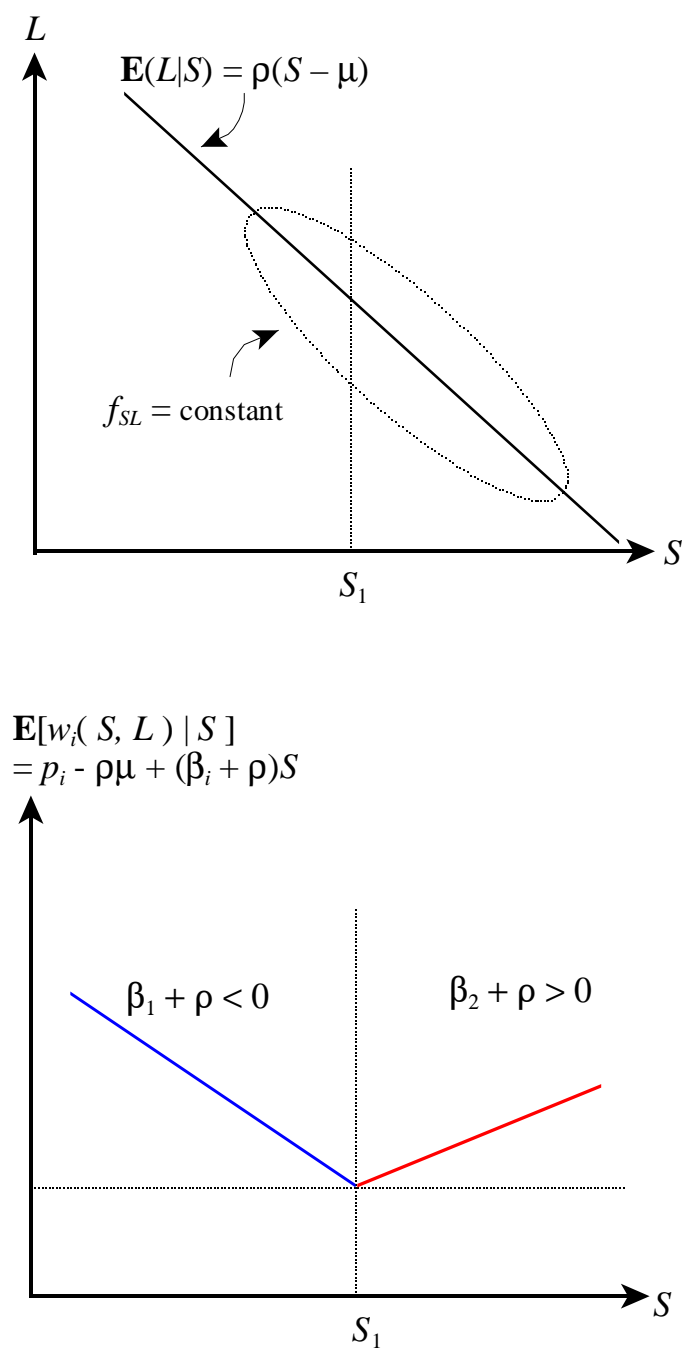

Figure 2: Income Distribution.

the case where $\rho<0$. The bottom panel plots $\mathbf{E}\left(w_{i}(S, L) \mid S\right)$ against $S$ for the case of two industries. This wage profile is piecewise linear with slope $\beta_{i}+\rho$ on $S \in\left(S_{i-1}, S_{i}\right)$. The $\beta$ and $\rho$ terms correspond to productivity and two-attribute sorting effects, respectively. Holding $L$ constant, $\partial w_{i}(S, L) / \partial S=\partial \ln t_{i}(S, L) / \partial S=\beta_{i}$. That is, workers with more $S$ produce more $t_{i}$ and hence earn more. This is the productivity effect. Further, $\partial \mathbf{E}(L \mid S) / \partial S=\rho$ i.e., the average amount of $L$ that an $S$ type has depends on $\rho$. If $\rho$ is negative then higher 
$S$ is associated with lower $L$ and hence with lower productivity and earnings. This is the two-attribute sorting effect.

Figure 2 displays the case where $\beta_{1}+\rho<0<\beta_{2}+\rho$ so that the two-attribute sorting effect dominates in industry 1 and the productivity effect dominates in industry 2. More generally, the average earnings profile illustrated in figure 2 can be downward sloping, Vshaped, or upward sloping. The message to be taken from this is that while $S$ determines worker sorting, it does not determine the amount of the other productive asset $L$ that workers bring to the workplace. Thus, $S$ alone does not determine output, earnings, or inequality.

\section{Have and Have-Not Economies $(\rho)$}

The next three sections describe the role of the distribution of endowments for the patterns of production and trade. We start with $\rho$. An economy with a high positive value of $\rho$ is a 'have and have-not' economy. Workers either have a lot of both $S$ and $L$ or have very little of both $S$ and $L$. International differences in $\rho$ are readily explained by a host of international differences in institutions and policies. For example, Sweden has a strong institutional bias towards redistribution and extensive social policies involving early childhood interventions which ensure that each worker obtains at least one marketable attribute. ${ }^{7}$ In contrast, in the United States where these institutions and policies are muted, the acquisition of $S$ and $L$ are more highly correlated because acquisition is driven by causes such as parental income that affect both $S$ and $L$. This is consistent with evidence that intergenerational mobility

\footnotetext{
${ }^{7}$ See Trefler (2004) for further discussion.
} 
is lower in the United States than in countries such as Sweden and Canada (Björklund and Jänti 1997; Blanden 2004). See Solon (2002) for a survey. Thus it is of interest to assume that the Swedish $\rho$ is smaller than the U.S. $\rho$. We now investigate the implications of this for the patterns of production and trade.

\subsection{Production: Rybczynski Revisited}

To get the flavour of things, let's return to the 2-industry example of figure 2 . The figure is reproduced on the right side of figure 3. The left side illustrates the case of $\rho>0$. A rise in $\rho$ causes $\mathbf{E}(L \mid S)=\rho(S-\mu)$ to pivot around the point $(\mu, 0)$. To keep figure 3 simple, we have drawn it for the case where $S_{1}=\mu$. Note that the rise in $\rho$ does not alter the sorting rule $S_{1}$. (See equation 5.) The bottom panels of figure 3 plot $\mathbf{E}\left(w_{i} \mid S\right)$. Since $\mathbf{E}\left(\ln t_{i} \mid S\right)=\mathbf{E}\left(w_{i} \mid S\right)-p_{i}$, the bottom-panel wage profiles are similar to the output profiles.

As $\rho$ rises the average level of $L$ falls for workers with endowment $S<S_{1}$ so that the average level of output $Y_{1}$ falls. For workers with endowment $S>S_{1}$, the opposite is true so that $Y_{2}$ rises. This is a Rybczynski-style result: as $\rho$ rises, $Y_{2}$ rises relative to $Y_{1}$. Rybczynski results typically hold in clear form only when there are two industries. A remarkable feature of our figure 3 result is that it holds for any number of industries.

Theorem 1. $d\left(Y_{i} / Y_{i-1}\right) / d \rho>0$ for $i=1,2, \ldots, n$. That is, an increase in the correlation between $S$ and $L$ increases the output of $S$-intensive industries relative to $L$-intensive industries.

The proof of the theorem is not difficult. However, it does requires some additional 


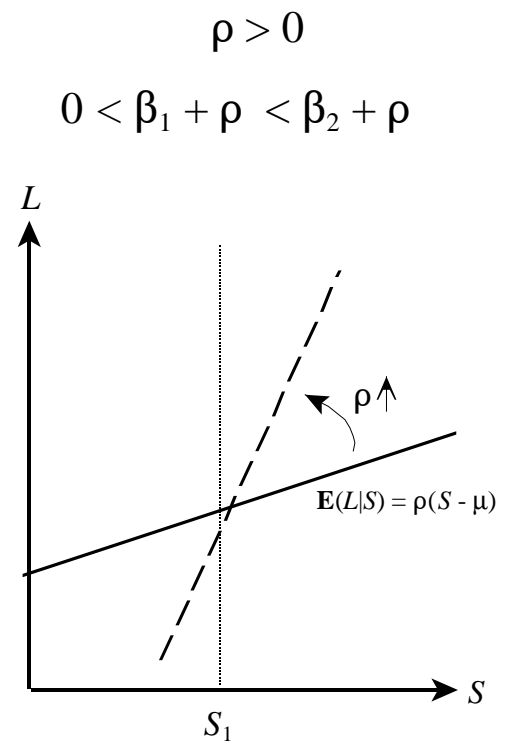

$$
\begin{gathered}
\rho<0 \\
\beta_{1}+\rho<0<\beta_{2}+\rho
\end{gathered}
$$
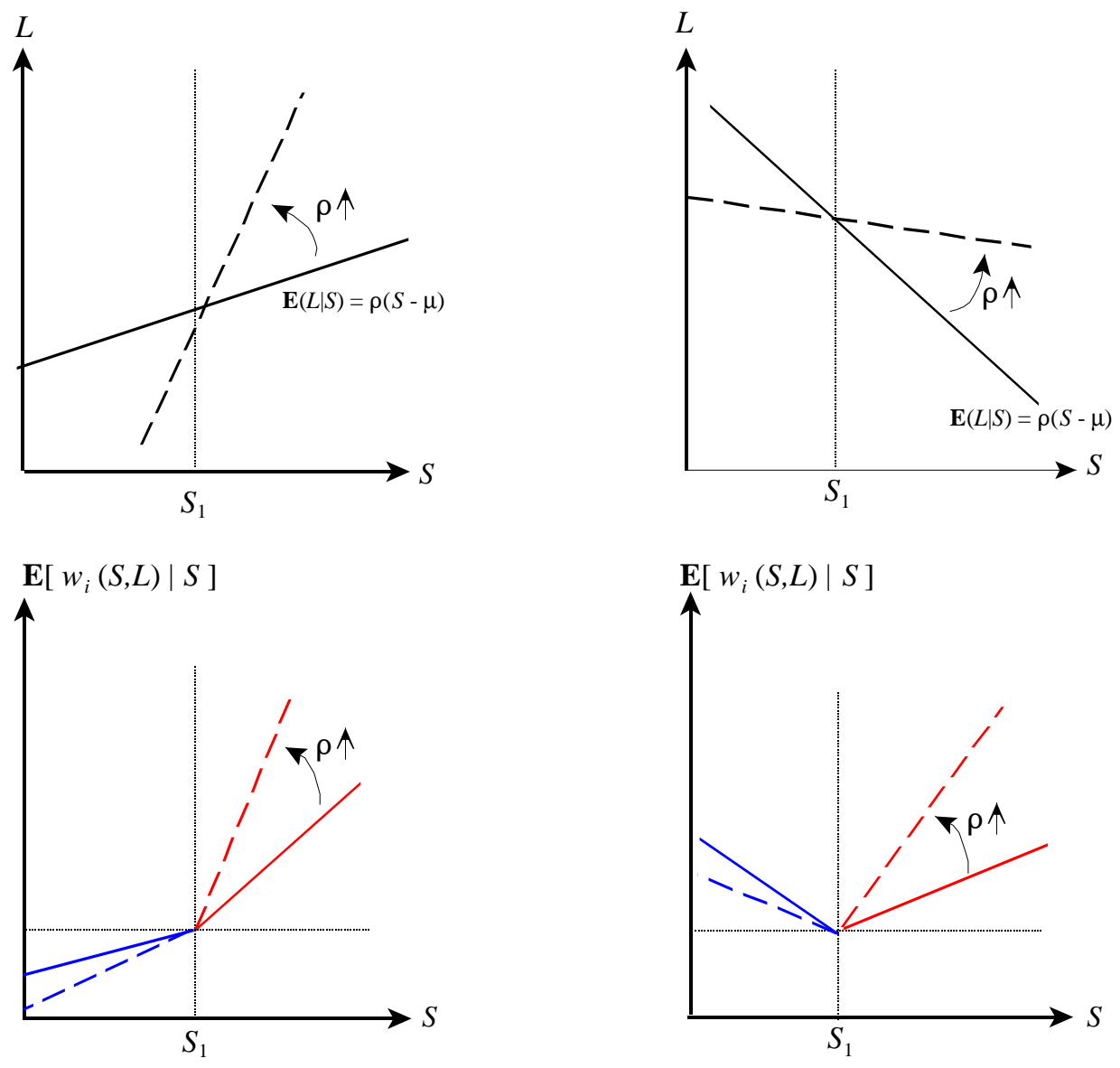

Figure 3: The Impact of $\rho$.

notation. Define

$$
S^{*} \equiv S-\mu \quad \text { and } \quad S_{i}^{*} \equiv S_{i}-\mu .
$$

Let $g\left(S^{*}, L\right)$ be an arbitrary function of $\left(S^{*}, L\right)$ and let $\mathbf{E}\left(g\left(S^{*}, L\right) \mid a<S^{*}<b\right)$ be the expectation of $g$ for those workers with an $S^{*}$ between $a$ and $b .^{8}$ The following lemma will be used repeatedly.

\footnotetext{
${ }^{8}$ If this is not clear see the precise mathematical statement in appendix equation (18).
} 
Lemma 1. Define $\mathbf{E}_{i}(x) \equiv \mathbf{E}\left(S^{*}+x \mid S_{i-1}^{*}-x<S^{*}<S_{i}^{*}-x\right), x \in \mathbb{R}$. Then $\mathbf{E}_{i-1}(\cdot)<$ $S_{i-1}^{*}<\mathbf{E}_{i}(\cdot)<S_{i}^{*}$.

Proof of Lemma 1: $S_{i-1}^{*}-x<S^{*}<S_{i}^{*}-x$ implies $S_{i-1}^{*}<S^{*}+x<S_{i}^{*}$. Hence $S_{i-1}^{*}<\mathbf{E}_{i}(\cdot)<S_{i}^{*}$. Likewise, $S_{i-2}^{*}<\mathbf{E}_{i-1}(\cdot)<S_{i-1}^{*}$ so that $\mathbf{E}_{i-1}(\cdot)<S_{i-1}^{*} \cdot$

Proof of Theorem 1: As shown in appendix D, differentiation of $Y_{i}$ with respect to $\rho$ yields

$$
\frac{d \ln Y_{i}}{d \rho}=\mathbf{E}_{i}\left(\beta_{i}+\rho\right)-\rho
$$

Hence $d \ln \left(Y_{i} / Y_{i-1}\right) / d \rho=\mathbf{E}_{i}\left(\beta_{i}+\rho\right)-\mathbf{E}_{i-1}\left(\beta_{i-1}+\rho\right)$. From lemma 1, $\mathbf{E}_{i}\left(\beta_{i}+\rho\right)>S_{i-1}^{*}>$ $\mathbf{E}_{i-1}\left(\beta_{i-1}+\rho\right)$ for $i>1$ so that $d \ln \left(Y_{i} / Y_{i-1}\right) / d \rho>0$.

As $\rho$ rises, $Y_{i}$ rises relative to $Y_{i-1}$. It would be nice to add to this the existence of an industry $i_{\rho}$ such that all industries $i>i_{\rho}$ expand and all industries $i \leq i_{\rho}$ contract. A sufficient condition for this is $S_{1}^{*}<\rho<S_{n-1}^{*}{ }^{9}$ With many industries so that industries 1 and $n$ are small (i.e., $S_{1}^{*}$ is a large negative number and $S_{n-1}^{*}$ is a large positive number) this condition will be satisfied.

\subsection{Trade: Heckscher-Ohlin Revisited}

In this section we consider trade patterns between two economies that differ only in terms of $\rho$. The conventional wisdom is that the similarity of endowments among Northern countries makes the Heckscher-Ohlin model irrelevant for describing North-North trade. Recent

\footnotetext{
${ }^{9}$ From lemma 1 and equation (11), $S_{i-1}^{*}<d \ln Y_{i} / d \rho+\rho=\mathbf{E}_{i}<S_{i}^{*}$. Hence $d \ln Y_{1} / d \rho<S_{1}^{*}-\rho$ which is negative for $S_{1}^{*}<\rho$. Further, $d \ln Y_{n} / d \rho>S_{n-1}^{*}-\rho$ which is positive for $S_{n-1}^{*}>\rho$. Since $d \ln Y_{i} / d \rho$ switches signs between $i=1$ and $i=n$ and is increasing in $i$ there must exist an $i_{\rho}$ such that $d \ln Y_{i} / d \rho>0$ $\Leftrightarrow i>i_{\rho}$.
} 
research suggests otherwise by pointing out that North-North trade is partly driven by subtle difference among Northern workforces in such dimensions as communication skills and team-work. For example, consider studies of workplace change involving new technologies combined with new forms of work organization such as team production, statistical process control, and total quality management. As Osterman (1995) points out, the most striking assessments of the productivity benefits of such workplace innovations are studies that contrast U.S. and foreign firms. There are two studies that will be known to economists. Bailey and Gersbach (1995) demonstrate that communication and team skills, in additional to technical skills, are much more important in German enterprises than in American enterprises. This results in a German comparative advantage in products involving long chains of production. Murnane and Levy (1996) review differences in the worker screening practices of U.S.-owned versus Japanese-owned auto plants located in the United States. Japanese interviewers focus on the ability to solve problems in changing environments, the ability to work in groups, and the ability to communicate effectively. Murnane and Levy (1996) then show that Japanese screening for these skills translates into higher productivity. These studies demonstrate that subtle differences in workers' skills are important for productivity and hence for comparative advantage.

To model this we begin by establishing that when there are only two industries, the low- $\rho$ economy has a higher autarky price of good 2 (relative to good 1) and hence a comparative advantage in the $L$-intensive industry 2. ${ }^{10}$ Assume that preferences are homothetic and identical internationally. Also assume that the economies are identical except for differences

\footnotetext{
${ }^{10}$ With more than two industries, we know that strong comparative advantage theorems do not hold and indeed comparative advantage is difficult to define e.g., Dixit and Norman (1980, page 6).
} 
in $\rho$. It follows from theorem 1 that in autarky the low- $\rho$ economy will have a low $Y_{2} / Y_{1}$ and hence a high relative price of good $2\left(\right.$ a high $\left.\ln q_{2}-\ln q_{1}\right)$. The opening up of trade will lower $\ln q_{2}-\ln q_{1}$. Since $p_{i} \equiv \ln \left(q_{i} A_{i}\right)$, the opening up of trade will lower $p_{2}-p_{1}$ and, from equation (5), raise $S_{1}$. The rise in $S_{1}$ leads to an expansion of industry 1 and a contraction of industry 2. Further, the lower $\ln q_{2}-\ln q_{1}$ raises consumer demand for industry 2 relative to industry 1 so that in equilibrium, the low- $\rho$ economy exports good 1 and imports good 2. That is, we obtain the standard comparative advantage results.

We turn next to a trade theorem for the multi-industry case. We make the usual Heckscher-Ohlin similarity assumptions.

Assumption 1. (i) Preferences are homothetic and identical internationally. (ii) Technology parameters $A_{i}$ and $\beta_{i}$ are identical internationally. (iii) Consumers in all countries face the same prices $q_{i}$. (iv) Trade is balanced.

Theorem 2. Let assumption 1 hold. Also assume that the distribution of endowments $f_{S L}(S, L)$ is the same internationally except that the correlation $\rho$ between $S$ and $L$ is larger at home than abroad. Then there exists a unique industry $i_{\rho}<n$ such that the home country exports all relatively $S$-intensive commodities $\left(i>i_{\rho}\right)$ and imports all relatively $L$-intensive commodities $\left(i \leq i_{\rho}\right)$.

The proof is simple and appears in appendix E. ${ }^{11}$

The Heckscher-Ohlin theorem predicts trade based on levels of $S$ and $L$. Theorem 2 predicts trade based on a higher moment of the distribution of endowments. Also, in

\footnotetext{
${ }^{11}$ If $i_{\rho}>1$ then it is possible that the imports of industry $i_{\rho}$ are 0 , but this requires a very particular set of parameter values.
} 
contrast to the Heckscher-Ohlin model our production and trade predictions are determinate and easily described even when there are more than two goods.

\subsection{Earnings and Inequality}

We have already seen in the bottom panels of figure 3 that as $\rho$ rises average earnings fall in $L$-intensive industries $\left(i \leq i_{\rho}\right)$ and rise in $S$-intensive industries $\left(i \geq i_{\rho}\right)$. This is a general result. From equations (9) and (10), $\mathbf{E}\left(w_{i}(S, L) \mid S_{i-1}^{*}<S^{*}<S_{i}^{*}\right)=p_{i}+\beta_{i} \mu+\left(\beta_{i}+\right.$ $\rho) \mathbf{E}\left(S^{*} \mid S_{i-1}^{*}<S^{*}<S_{i}^{*}\right)$ is linear in $\rho$. Hence

$$
\frac{d \mathbf{E}\left(w_{i}(S, L) \mid S_{i-1}^{*}<S^{*}<S_{i}^{*}\right)}{d \rho}=\mathbf{E}\left(S^{*} \mid S_{i-1}^{*}<S^{*}<S_{i}^{*}\right) \equiv \mathbf{E}_{i}(0) .
$$

This implies that as $\rho$ rises average earnings fall in $L$-intensive industries and rise in $S$ intensive industries. ${ }^{12}$ Thus, when comparing Sweden with the United States, the high$\rho$ U.S. economy will have higher average wages in $S$-intensive industries as compared to Sweden. The U.S. will also have lower average wages in $L$-intensive industries as compared to Sweden.

We next turn to inequality. Our model has a lot to say about within-industry inequality as measured by the variance of log earnings within an industry. To keep the notation simple, let $\mathbf{V}\left(w_{i}(S, L) \mid i\right)$ be the variance of wages conditional on choosing industry $i$ (that is, conditional on $S_{i-1}^{*}<S^{*}<S_{i}^{*}$ ). From appendix equation (26), this is just

\footnotetext{
${ }^{12}$ This follows from two facts. First, by lemma 1 the derivative is increasing in $i$. Second, $\mathbf{E}\left(S^{*} \mid S_{0}^{*}<S^{*}<S_{1}^{*}\right)=\mathbf{E}\left(S^{*} \mid S^{*}<S_{1}^{*}\right)<\mathbf{E}\left(S^{*}\right)=0$ and $\mathbf{E}\left(S^{*} \mid S_{n-1}^{*}<S^{*}<S_{n}^{*}\right)=\mathbf{E}\left(S^{*} \mid S_{n-1}^{*}<S^{*}\right)>$ $\mathbf{E}\left(S^{*}\right)=0$ so that the derivative is negative for $i$ below some cut-off and positive for $i$ above that cut-off.
} 


$$
\mathbf{V}\left(w_{i}(S, L) \mid i\right)=\left(1-\rho^{2}\right)+\left(\beta_{i}+\rho\right)^{2} \mathbf{V}\left(S^{*} \mid i\right)
$$

The term $1-\rho^{2}$ is the within-group variance where 'group' is defined as the set of workers with the same $S .\left(\beta_{i}+\rho\right)^{2} \mathbf{V}\left(S^{*} \mid i\right)$ is the between-group variance. ${ }^{13}$ Thus a rise in $\rho$ has within-group and between-group effects on inequality. In the case where $\rho<0$ and $\beta_{i}+\rho>0$ for all $i$, the within- and between-group effects move in the same direction. The high- $\rho$ economy will have higher within-group, between-group, and within-industry inequality in all industries.

Much of the empirical work on trade and wages has focussed on between-group inequality e.g., production-nonproduction worker wage differentials. When $\rho>0$, as it most certainly is in the United States, between-group inequality is rising in $\rho$.

One conclusion that emerges from this section is the care that is needed in isolating the effects of trade on inequality. $\rho$ determines both the pattern of trade and the level of earnings inequality. A $\rho$ that is higher in the United States than in Sweden causes both U.S.-Swedish trade and higher between-group inequality in the United States than in Sweden. In trying to assess the impact of trade on inequality in cross-country studies one must therefore be very careful to ensure that the correlation between trade and inequality is not being driven by a third, unobserved factor, namely $\rho$.

\footnotetext{
${ }^{13}$ At the risk of some difficult but obvious notation, the standard within-between decomposition may be written as

$$
\mathbf{V}\left(w_{i}(S, L) \mid i\right)=\mathbf{E}\left[\mathbf{V}\left(w_{i}(S, L) \mid S\right) \mid i\right]+\mathbf{V}\left[\mathbf{E}\left(w_{i}(S, L) \mid S\right) \mid i\right]
$$

where the first and second terms on the right are the within-group and between-group variances, respectively.
} 


\section{Endowment inequality}

We next turn to the role of endowment inequality. Consider two economies, one of which has more mass in the tails of its bivariate density $f_{S L}(S, L)$ and hence has more individuals with extreme values of either $S$ or $L$. This will have implications for trade flows and inequality that are related to those discussed in Grossman and Maggi (2000) and Grossman (2004). As noted in the introduction, our trade mechanism is related to the Grossman and Maggi (2000) supermodularity mechanism and our inequality mechanism is very different from the Grossman (2004) incomplete-contracts mechanism. To focus ideas consider first a simple example with 3 goods: movies, information technologies, and machinery. The production of Hollywood flicks is intensive in creativity $L$ and the production of Silicon Valley information technologies is intensive in numericity $S$. In contrast, machinery is an 'O-Ring' reliable good whose production involves many components and whose overall reliability is the reliability of the least reliable component. Reliability therefore depends on a mix of worker skills in the sense of requiring both $L$ and $S$. If, say, the United States has a more unequal distribution of endowments than Germany, then the United States will export movies and information technologies to Germany and Germany will export machinery to the United States.

Formalizing this is tricky because there is no good definition of 'greater inequality' for bivariate distributions. We proceed by defining a form of mean-preserving spread for bivariate distributions. To ease notation we have been setting the variance of $S(\sigma)$ and the variance of $L\left(\sigma_{L}\right)$ to unity. In this section we reintroduce $\sigma$ and $\sigma_{L}$ explicitly. We define a bivariate mean-preserving spread as an increase in $\sigma$ and $\sigma_{L}$ that does not change means $\mathbf{E}(S) \equiv \mu$ and $\mathbf{E}(L) \equiv 0$ or conditional means $\mathbf{E}(L \mid S) \equiv \rho \sigma_{L}(S-\mu) / \sigma$ and $\mathbf{E}(S \mid L) \equiv \mu+\rho \sigma(L-0) / \sigma_{L}$. 
This is satisfied by increases in $\sigma$ and $\sigma_{L}$ that leave $\sigma / \sigma_{L}$ unchanged. Let $\gamma$ be an index of endowment inequality and let $\sigma(\gamma)$ and $\sigma_{L}(\gamma)$ be increasing unit-elastic functions so that $d \ln \left(\sigma / \sigma_{L}\right) / d \ln \gamma=0$. Then an increase in $\gamma$ raises variances $\sigma$ and $\sigma_{L}$ without affecting means or conditional means. We associate an increase in endowment inequality with an increase in $\gamma \cdot{ }^{14}$

\subsection{Production: Rybczynski Revisited}

An increase in $\gamma$ has no effect on the sorting rule (the $S_{i}$ ) nor our diagrams. All that an increase in $\gamma$ does is redistribute the mass of $f_{S L}$ away from its middle towards its tails. Therefore, the most $L$-intensive and $S$-intensive industries attract more workers and experience a relative rise in output.

Theorem 3. Consider an increase in endowment inequality $\gamma$. There exists a generically unique industry $i_{\gamma}$ with $i_{\gamma}<n$ and with the following properties.

(1) Consider two L-intensive industries i.e., industries with $i \leq i_{\gamma}$. Then as inequality rises, the more L-intensive of the two industries experiences a relative increase in output: $d\left(Y_{i-1} / Y_{i}\right) / d \gamma>0$ for all $i \leq i_{\gamma}$.

(2) Consider two $S$-intensive industries i.e., industries with $i>i_{\gamma}$. Then as inequality rises, the more $S$-intensive of the two industries experiences a relative increase in output: $d\left(Y_{i} / Y_{i-1}\right) / d \gamma>0$ for all $i \geq i_{\gamma}+1$.

\footnotetext{
${ }^{14}$ This parametrization of inequality satisfies Atkinson and Bourguignon's (1982) multivariate generalization of second-order stochastic dominance, which they use to measure bivariate inequality.
} 
When $i_{\gamma}>1$, part (1) states that $d Y_{1} / d \gamma>d Y_{2} / d \gamma>\ldots>d Y_{i_{\gamma}} / d \gamma$ and part (2) states that $d Y_{n} / d \gamma>d Y_{n-1} / d \gamma>\ldots>d Y_{i_{\gamma}} / d \gamma$. That is, the most $L$-intensive and $S$-intensive industries expand relative to industries near $i_{\gamma}$.

Proof: The proof is not difficult, but requires some notation. Define

$$
\mathbf{E}_{i}^{2}(x)=\mathbf{E}_{i}\left[\left(S^{*}+x\right)^{2} \mid S_{i-1}^{*}-x<S^{*}<S_{i}^{*}-x\right] .
$$

Then as shown in appendix $\mathrm{F}$, differentiation of $Y_{i}$ with respect to $\gamma$ yields

$$
\frac{d \ln Y_{i}}{d \ln \gamma}=\mathbf{E}_{i}^{2}\left(\beta_{i} \sigma+\rho \sigma_{L}\right)+\sigma_{L}^{2}\left(1-\rho^{2}\right)-1
$$

Let $i_{\gamma}$ be the industry for which $S_{i_{\gamma-1}}^{*}<0 \leq S_{i_{\gamma}}^{*}$. Without loss of generality we ignore the integer constraint and let $i_{\gamma}$ be the industry for which $S_{i_{\gamma}}^{*}=0$.

Consider part (1) of the theorem where $i \leq i_{\gamma}$ so that $S_{i-1}^{*}<S_{i}^{*} \leq 0$. In this case, the equation (12) condition $S_{i-1}^{*}-x<S^{*}<S_{i}^{*}-x$ implies $S_{i-1}^{*}<S^{*}+x<S_{i}^{*}<0$ or $S_{i}^{* 2}<\left(S^{*}+x\right)^{2}<S_{i-1}^{* 2}$. Further, this is true for all $x$. Restated, $S_{i}^{* 2}<\mathbf{E}_{i}^{2}(\cdot)<S_{i-1}^{* 2}$. It follows that $\mathbf{E}_{i}^{2}(\cdot)<S_{i-1}^{* 2}<\mathbf{E}_{i-1}^{2}(\cdot)$. Thus, $d \ln \left(Y_{i-1} / Y_{i}\right) / d \ln \gamma=\mathbf{E}_{i-1}^{2}\left(\beta_{i-1} \sigma+\rho \sigma_{L}\right)-$ $\mathbf{E}_{i}^{2}\left(\beta_{i} \sigma+\rho \sigma_{L}\right)>0$.

Now consider part (2) of the theorem where $i \geq i_{\gamma}+2$ so that $0 \leq S_{i-2}^{*}<S_{i-1}^{* 2}<S_{i}^{*}$. In this case, $S_{i-1}^{*}-x<S^{*}<S_{i}^{*}-x$ implies $S_{i-1}^{* 2}<\left(S^{*}+x\right)^{2}<S_{i}^{* 2}$. Further, this is true for all $x$. Restated, $S_{i-1}^{* 2}<\mathbf{E}_{i}^{2}(\cdot)<S_{i}^{* 2}$. It follows that $\mathbf{E}_{i-1}^{2}(\cdot)<S_{i-1}^{* 2}<\mathbf{E}_{i}^{2}(\cdot)$. Thus, $d \ln \left(Y_{i} / Y_{i-1}\right) / d \ln \gamma=\mathbf{E}_{i}^{2}\left(\beta_{i} \sigma+\rho \sigma_{L}\right)-\mathbf{E}_{i-1}^{2}\left(\beta_{i-1} \sigma+\rho \sigma_{L}\right)>0$. 
Finally, consider part (2) of the theorem where $i=i_{\gamma}+1$. If $\mathbf{E}_{i_{\gamma}+1}^{2}\left(\beta_{i_{\gamma}+1} \sigma+\rho \sigma_{L}\right)>$ $\mathbf{E}_{i_{\gamma}}^{2}\left(\beta_{i_{\gamma}} \sigma+\rho \sigma_{L}\right)$ then $d \ln \left(Y_{i_{\gamma}+1} / Y_{i_{\gamma}}\right) / d \ln \gamma>0$ and we are done. If $\mathbf{E}_{i_{\gamma}+1}^{2}\left(\beta_{i_{\gamma}+1} \sigma+\rho \sigma_{L}\right)<$ $\mathbf{E}_{i_{\gamma}}^{2}\left(\beta_{i_{\gamma}} \sigma+\rho \sigma_{L}\right)$ then $d \ln \left(Y_{i-1} / Y_{i}\right) / d \ln \gamma>0$ for $i=i_{\gamma}+1$ and the proof follows with $i_{\gamma}$ replaced by $i_{\gamma}+1$ in the statement of the theorem. ${ }^{15}$

\subsection{Trade: Heckscher-Ohlin Revisited}

North-North trade is left unexplained by the standard Heckscher-Ohlin model because average levels of endowments are similar across industrialized countries. Industrialized countries, however, differ in the inequality with which endowments are distributed. Theorem 3 shows that international differences in Northern production patterns can be driven by endowment inequality. This has immediate implications for trade.

First consider a comparison of autarky with free trade. Let assumption 1 hold and suppose that there are only two countries, $A$ and $B$, with country $A$ having the higher level of endowment inequality $\gamma$. Theorem 3 implies that in autarky country $A$ produces more of the most $L$ - and $S$-intensive goods than does country $B$. Hence $A$ has a lower relative price for these goods than does $B$. Hence, country $A$ 's comparative advantage lies with the most $L$ - and $S$-intensive goods and $A$ exports these goods while importing moderately $L$ - and $S$-intensive goods. Restated, endowment inequality is a source of comparative advantage for $L$ - and $S$-intensive goods.

To formalize this we will need $i_{\gamma}$ in theorem 3 to be greater than 1 so that there is at

\footnotetext{
${ }^{15}$ If $\mathbf{E}_{i_{\gamma}+1}^{2}\left(\beta_{i_{\gamma}+1} \sigma+\rho \sigma_{L}\right)=\mathbf{E}_{i_{\gamma}}^{2}\left(\beta_{i_{\gamma}} \sigma+\rho \sigma_{L}\right)$ then theorem 3 holds both for $i_{\gamma}$ and $i_{\gamma}+1$. This means that $i_{\gamma}$ is not unique and that $d \ln \left(Y_{i_{\gamma}+1} / Y_{i_{\gamma}}\right) / d \ln \gamma=0$, both of which violate the theorem. However, for almost all parameters (i.e., generically), $\mathbf{E}_{i_{\gamma}+1}^{2}\left(\beta_{i_{\gamma}+1} \sigma+\rho \sigma_{L}\right) \neq \mathbf{E}_{i_{\gamma}}^{2}\left(\beta_{i_{\gamma}} \sigma+\rho \sigma_{L}\right)$. It follows that $i_{\gamma}$ is generically unique and that $d \ln \left(Y_{i_{\gamma}+1} / Y_{i_{\gamma}}\right) / d \ln \gamma>0$ generically.
} 
least one extremely $L$-intensive industry $(i=1)$.

Theorem 4. Let assumption 1 hold and assume that $i_{\gamma}>1$. Also assume that the distribution of endowments is more unequal in the home country than in the rest of the world i.e., the home country has a larger $\gamma$ than the rest of the world. Then there exist two industries $\underline{i}_{\gamma}$ and $\bar{i}_{\gamma}$ (with $1 \leq \underline{i}_{\gamma}<\bar{i}_{\gamma} \leq n$ ) such that the home country imports all goods $i$ with $\underline{i}_{\gamma}<i<\bar{i}_{\gamma}$ and exports all other goods. That is, the home country exports all goods that are either extremely $L$-intensive $\left(i \leq \underline{i}_{\gamma}\right)$ or extremely S-intensive $\left(i \geq \bar{i}_{\gamma}\right)$.

The proof is relegated to appendix G.

Theorem 4 demonstrates that differences in endowment inequality provide a coherent account of trade between rich countries. To return to our example above, the United States has greater endowment inequality than Germany. As a result, the United States has a comparative advantage in Hollywood flicks, which intensively use creativity $L$. The United States also has a comparative advantage in Silicon Valley information technologies, which intensively use numericity $S$. On the other hand, Germany has a comparative advantage in machinery and other 'O-ring' reliable goods produced using long chains of production and for which each link requires moderate levels of both $S$ and $L$ in order to ensure reliability.

Our model also provides implications for inequality. We state without proof that the country with greater endowment inequality will have greater within-industry inequality $\mathbf{V}\left(w_{i}(S, L) \mid i\right)$ in all industries. 


\section{Average endowments}

We finish up our discussion of endowments and trade with the role of the average level of endowments. This is a standard Heckscher-Ohlin exercise. Intuitively, a country with a high average $S$ per worker (i.e., a high $\mu$ ) should have production patterns that are skewed towards $S$-intensive goods. This in turn should lead the country to export $S$-intensive goods.

Theorem 5. $d\left(Y_{i} / Y_{i-1}\right) / d \mu>0$ for $i>1$. That is, an increase in the mean level of $S$ increases the relative output of $S$-intensive industries.

Proof of Theorem 5: As shown in appendix H, differentiation of $Y_{i}$ with respect to $\mu$ yields

$$
\sigma \frac{d \ln Y_{i}}{d \mu}=\mathbf{E}_{i}\left(\beta_{i}+\rho\right)-\rho
$$

where $\mathbf{E}_{i}$ is defined in lemma 1 . Hence lemma 1 establishes that $d \ln Y_{i} / d \ln \mu$ is increasing in $i$.

As in the discussion following theorem 1, if there are many small industries then there will be an industry $i_{\mu}$ such that output expands for the most $S$-intensive industries $\left(i \geq i_{\mu}\right)$ and contracts for the most $L$-intensive industries $\left(i<i_{\mu}\right)$. Note that $i_{\mu}$ is the same industry as the $i_{\rho}$ industry in theorems 1 and 2 .

The Rybczynski theorem 5 has immediate implications for trade flows.

Theorem 6. Let assumption 1 hold. Also assume that the home country is more $S$ abundant than the foreign country in the sense of having a larger $\mu$. Then there exists a unique industry $i_{\mu}>1$ such that the home country exports all relatively $S$-intensive commodities $i \geq i_{\mu}$ and imports all relatively $L$-intensive commodities $i<i_{\mu}$. 
See appendix I for the proof.

This is our counterpart to the Heckscher-Ohlin theorem. Note that we have obtained it without reference to the number of goods, cones of diversification or factor price equalization.

\section{The Political Economy of Protection}

Although workers can move costlessly from industry to industry, our labour market does not behave as in the Heckscher-Ohlin model. Rather, it behaves as a hybrid of the HeckscherOhlin and Specific Factors labour markets. This leads to demands for protection that partly coalesce around factor-based lobbies as in the Stolper-Samuelson theorem and partly coalesce around industry-based lobbies as in the Specific Factors model.

Key to our political economy prediction is the rent-seeking behaviour of workers. To see this, consider the arrow in figure 4 . A type $S$ worker who has selected into industry $i$ earns discretely more in industry $i$ than in any other industry. From the worker's perspective, this earnings differential can be thought of as a rent associated with the existence of industry $i .^{16}$ Now consider a tariff that raises the industry price $q_{i}$. Since $w_{i}(S, L)-L=\ln q_{i}+\ln A_{i}+\beta_{i} S$, the tariff shifts up the industry- $i$ wage profile while leaving all other industry wage profiles unchanged.

Which workers demand this protection? Workers near the middle of the interval $\left[S_{i-1}, S_{i}\right]$ are endogenously immobile in the sense that it will take almost total industry collapse to induce them to switch industries. These workers demand protection for their industry and only their industry. To the extent that they succeed in organizing a lobby, the lobby will

\footnotetext{
${ }^{16}$ Of course, the worker is paid the value of her marginal product and in this sense there are no rents.
} 


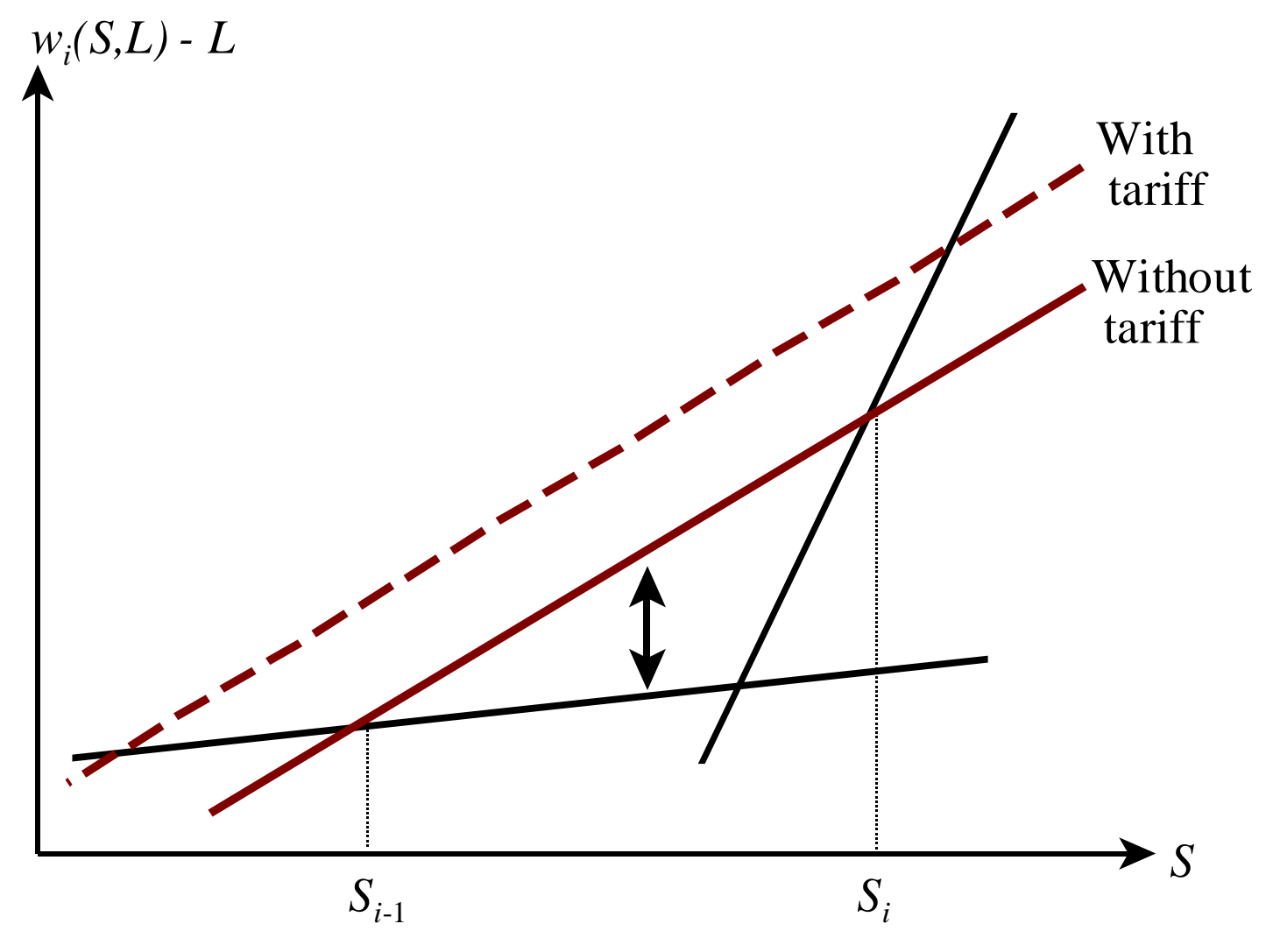

Figure 4: The Endogeneity of Specificity.

be industry-based as in the Specific Factors model. Workers who are near the boundary $S_{i-1}$ are endogenously mobile in the sense that they will switch into industry $i$ if industry $i$ receives a tariff and switch into industry $i-1$ if industry $i-1$ receives a tariff. These workers do not demand protection for a particular industry. Rather, they demand protection for industries that intensively use worker types near $S_{i-1}$. To the extent that such workers succeed in organizing a lobby, the lobby will consist exclusively of workers whose $S$ is near $S_{i-1}$. That is, the lobby will be factor-based as in the Stolper-Samuelson theorem.

Such heterogeneous worker responses to changes in industry fortunes are frequently observed in the data. In response to impending mass lay-offs, workers who stay with the firm 
typically do better than those who are laid off, but do less well than those who voluntarily quit. This is indicative of worker sorting. Workers who quit are closer to $S_{i-1}$ while those who are laid off are closer to the middle of the interval. Jacobson et al. (1993) provide strong evidence on these points using data drawn from the early 1980s import surge that devastated the Pennsylvania steel industry. Casual empiricism suggests many other examples e.g., union members often disagree about whether or not to strike - workers near $S_{i-1}$, who have good outside options, are less supportive of a strike than workers near the middle of the interval $\left[S_{i-1}, S_{i}\right]$.

Returning to our prediction that industry-based and factor-based lobbies will coexist, note that there is now abundant evidence that the Stolper-Samuelson and Specific Factor lobbying predictions are both partially supported by the evidence. Magee et al. (1989) and Goldberg and Maggi (1999) find evidence in support of the proposition that industry-based lobbying is important. Rogowski (1989), O'Rourke and Williamson (1999) and Slaughter and Scheve (2001) present evidence in favour of the proposition that factor-based lobbying is important. Trefler (1993) and Beaulieu (2002) find evidence of both factor-based and industry-based trade policy preferences. The coexistence of industry- and factor-based lobbying is always explained away by noting that industry-based lobbying dominates in the short run while factor-based lobbying dominates in the long run as immobile factors melt into mobility. However, the evidence for factor-based lobbying in Trefler (1993), Slaughter and Scheve (2001) and Beaulieu (2002) is short run. Further, many industry lobbies have succeeded in obtaining long-run protection. For example, the steel industry has been protected since the 1960s despite the fact that all of its 1960s capital stock was written off 
due to the introduction of new technologies such as the 'mini mill'. A simplistic distinction between long and short periods is clearly not rich enough to explain the coexistence of industry- and factor-based lobbying. Our model points to the need for identifying the degree of worker specificity and shows clearly how this is to be estimated in terms of a standard econometric sorting model. Our model also shows that the degree of specificity and how it evolves in response to industry shocks is central for explaining the evolution of international trade protection.

Finally, despite important similarities between our model and the Specific Factors model, there are important differences. We have already seen one. In the Specific Factors model the specific factor is homogeneous. In our model the specific factor is heterogeneous and this heterogeneity is both what generates upward-sloping industry supply functions and what generates the coexistence of industry- and factor-based lobbying. A second difference is that in the Specific Factors model the specific factor is exogenous, as is its distribution across industries. In our model the degree of specificity and the distribution of the specific factor across industries is endogenous. This provides both a deeper level of explanation and results in sharper predictions about trade and the political economy of protection.

\section{International Technology Differences}

In the Ricardian model and in extensions to the Heckscher-Ohlin model, international technology differences typically lead to specialization. This is hard to reconcile with work by Pack (1984) and others on the international coexistence of different vintages of technology. In our model, a country using an inferior technology can still compete by essentially skim- 


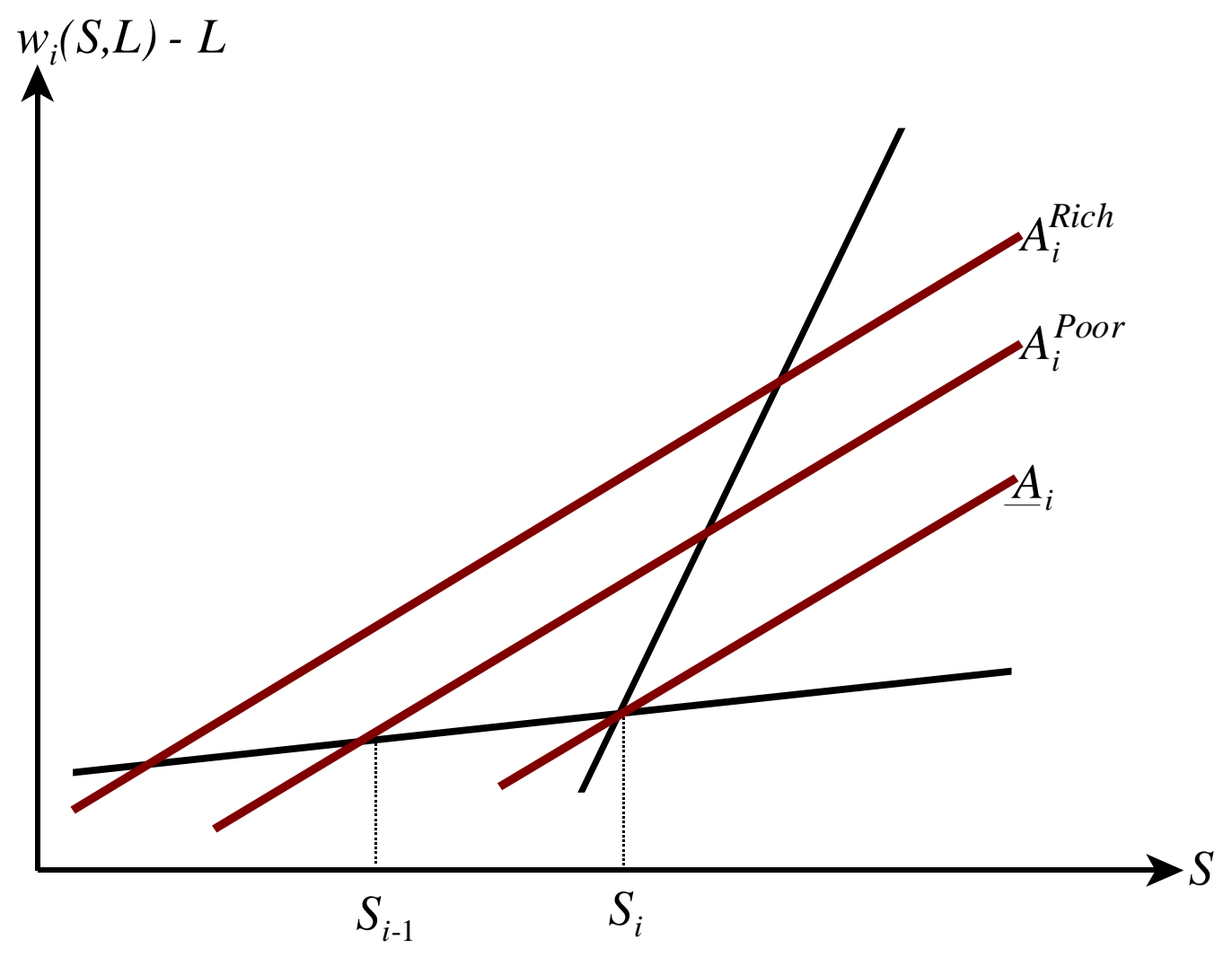

Figure 5: International Technology Differences Without Specialization.

ming the cream, that is, by operating at a smaller level of output and employing only those few workers whose skills are almost a perfect match for the industry's needs. Poor countries compete by foregoing all rents associated with these skills.

More formally, consider figure 5 which plots the wage profiles $w_{i}(S, L)-L=\ln q_{i}+$ $\ln A_{i}+\beta_{i} S$. Recall that $A_{i}$ is a Hicks-neutral productivity parameter. Since rich countries typically have higher productivity than poor countries, assume $A_{i}^{\text {Rich }}>A_{i}^{\text {Poor }}$. Consider the profiles labeled $A_{i}^{\text {Rich }}$ and $A_{i}^{\text {Poor }}$. Although $A_{i}^{\text {Rich }}>A_{i}^{\text {Poor }}$, the poor country continues to produce good $i$. That is, international technology differences need not lead to Ricardian specialization. Poor countries compete by accepting lower wages. Comparing identical 
workers in rich and poor countries, the ratio of wages will be $A_{i}^{\text {Rich }} / A_{i}^{\text {Poor }}$.

How large can international technology differences be before there is Ricardian specialization i.e., before the rich country becomes the sole producer of $i$ ? When $A_{i}^{\text {Poor }}$ drops to $\underline{A}_{i}$ or below, the poor country is so unproductive in industry $i$ that the poor-country industry shuts down. $\underline{A}_{i}$ is trivial to compute. Noting from equations (2)-(5) that $S_{i-1}$ and $S_{i}$ are linear in $A_{i}, \underline{A}_{i}$ satisfies the linear equation $S_{i-1}\left(\underline{A}_{i}\right)=S_{i}\left(\underline{A}_{i}\right)$. The next theorem formalizes these points and offers a trade prediction.

Theorem 7. Consider international differences in technology $A_{i}$.

1. A rise in $A_{i}$ raises output in industry $i\left(d Y_{i} / d A_{i}>0\right)$, lowers output in industries $i-1$ and $i+1\left(d Y_{i-1} / d A_{i}<0, d Y_{i+1} / d A_{i}<0\right)$, and leaves output in all other industries unchanged $\left(d Y_{j} / d A_{i}=0\right.$ for $\left.j \neq i-1, i, i+1\right)$.

2. Let assumption 1 hold except that $A_{i}$ is higher in the home country than in the foreign country. (a) If $A_{i}>\underline{A}_{i}$ in both countries then good $i$ is produced in both countries. (b) The home country exports good $i$ while importing goods $i-1$ and $i+1$.

With only two goods, the theorem reduces to the standard Ricardian result, namely, $d Y_{2} / d A_{2}>$ $0>d Y_{1} / d A_{2}$ and the home country exports good 2 while importing good 1 . However, with only two goods $-\infty=S_{0}<S_{1}<S_{2}=\infty$ i.e., both countries must produce both goods. Thus, sharp Ricardian specialization cannot occur. 


\section{Trade and Inequality}

The Heckman and Sedlacek model that we are using, and indeed most variants of the Roy model of labour markets, yield very rich predictions about the determinants of inequality. Given length constraints of this paper, we focus on within-industry inequality. Despite the importance of within-industry inequality - after all, trade policy is typically conducted at the industry level - within-industry inequality has received virtually no attention. Bartel and Sicherman (1999) is the exception.

Consider a tariff-induced increase in the price of good $i$. As in figure 4, this expands both ends of the interval $\left[S_{i-1}, S_{i}\right]$. Recall from figure 2 that average wages take on their extreme values at $S=S_{i-1}$ and $S=S_{i} \cdot{ }^{17}$ Thus, within-industry inequality rises because the tariff attracts workers both with very high and very low wages. Theorem 8 formalizes this.

Theorem 8. An increase in the industry $i$ price (due perhaps to a tariff) raises inequality in the industry:

$$
\frac{d \mathbf{V}\left(w_{i}(S, L) \mid i\right)}{d q_{i}}=\frac{\left(\beta_{i}+\rho\right)^{2}}{\beta_{i+1}-\beta_{i}} \frac{d \mathbf{V}\left(S^{*} \mid i\right)}{d S_{i}^{*}}-\frac{\left(\beta_{i}+\rho\right)^{2}}{\beta_{i}-\beta_{i-1}} \frac{d \mathbf{V}\left(S^{*} \mid i\right)}{d S_{i-1}^{*}}>0
$$

Further, an increase in the industry $i$ price lowers inequality in industries $i-1$ and $i+1$ :

$$
\frac{d \mathbf{V}\left(w_{i-1}(S, L) \mid i-1\right)}{d q_{i}}<0 \quad \text { and } \quad \frac{\mathbf{V}\left(w_{i+1}(S, L) \mid i+1\right)}{d q_{i}}<0
$$

\footnotetext{
${ }^{17}$ If $\beta_{i}+\rho>0$ then $S=S_{i}$ is the maximum of $\mathbf{E}\left(w_{i}(S, L) \mid S\right)$ and $S=S_{i-1}$ is the minimum. If $\beta_{i}+\rho<0$ then $S=S_{i}$ is the minimum and $S=S_{i-1}$ is the maximum.
} 
The proof appears in appendix $\mathrm{K}$ and uses the fact that $d \mathbf{V}\left(S^{*} \mid i\right) / d S_{i}^{*}>0$ and $d \mathbf{V}\left(S^{*} \mid i\right) / d S_{i-1}^{*}<$ 0 . We emphasize that international trade impacts on inequality only via the sorting rule i.e., only via the impact of $q_{i}$ on $S_{i}$ and $S_{i-1}^{*} \cdot{ }^{18}$

It is tempting to argue that international trade must either lower or raise inequality in all industries. Theorem 8 make it clear that international trade can raise inequality in some industries while lowering inequality in others. To investigate further we calculated changes in within-industry inequality using 1984-1994 Current Population Survey data. We found that 1984-94 changes in $\mathbf{V}\left(w_{i}(S, L) \mid i\right)$ ranged from -0.06 in Logging to +0.11 in Footwear. Thus, despite rising inequality economy-wide, changes in industry-level inequality have varied widely across industries. Equation (15) serves as a basis for investigating whether this variation can be explained by industry-specific trade shocks.

This leads us naturally to a discussion of how within-industry inequality is impacted by international trade (changes in $q_{i}$ ) versus skill-biased technical change (changes in $\beta_{i}$ ). Both of these alter the sorting rule $S_{i}=\left(q_{i}-q_{i+1}+A_{i}-A_{i+1}\right) /\left(\beta_{i+1}-\beta_{i}\right)$. However, only skill-biased technical change has direct effects on inequality. The reason is a deep one. Earnings depend on price multiplicatively so that a price change has a proportionate effect on the earnings of all workers in the industry. Restated, $q_{i}$ has no direct effect on the within-industry variance of log earnings. $q_{i}$ operates only via the sorting rule. In contrast, skill biased technical change has the direct effect of making $S$ more productive. Figure 6 illustrates this point.

In the left-hand panel of figure 6 , a rise in the price of industry 2 raises inequality in

\footnotetext{
${ }^{18}$ All the key insights of this section hold when we additionally condition on observable worker characteristics such as $L$ i.e., when we investigate $\mathbf{V}\left(w_{i}(S, L) \mid L, i\right)$.
} 
International Trade

(Rise in $q_{2}$ )

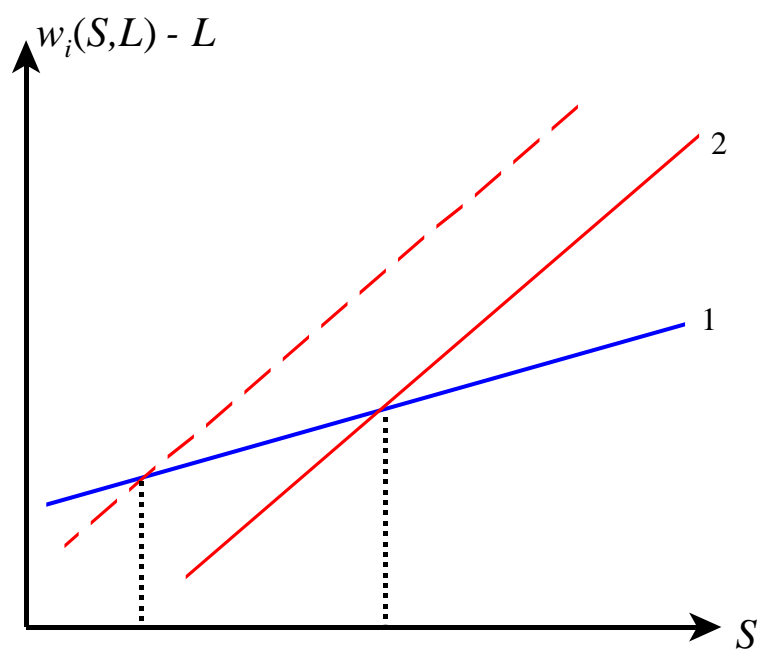

Skill Biased Technical Change (Rise in $\beta_{2}$ )

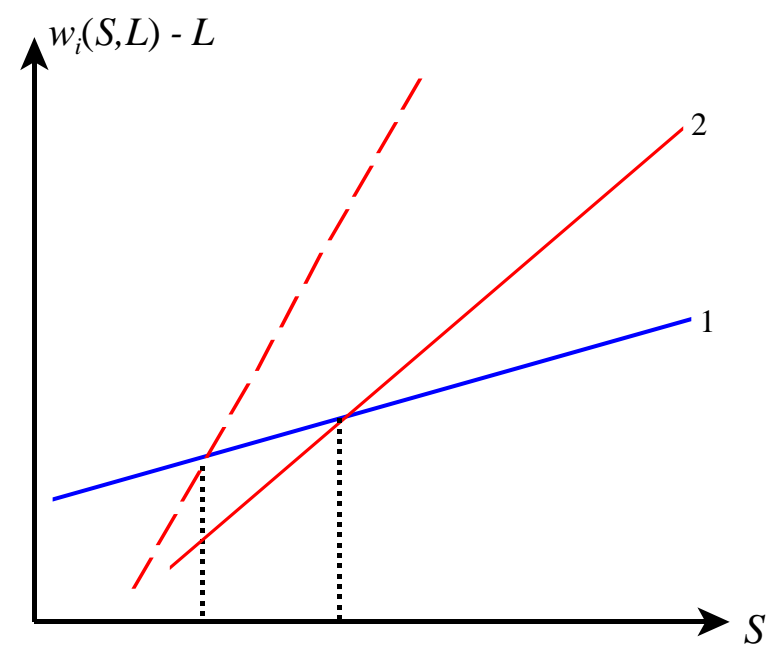

Figure 6: Trade Versus Skill Biased Technical Change.

industry 2 and lowers it in industry 1 . This occurs as a result of worker sorting. ${ }^{19}$ In contrast, not only does skill biased technical change affect the sorting rule, it also affects the productivity of $S$. This appears in the right-hand panel of figure 6 where a rise in $\beta_{2}$ steepens the earnings profile of industry 2. A rise in $\beta_{2}$ can increase or decrease $S_{1}$. In figure 6 we illustrate the case where skill biased technical change decreases $S_{1}$. In this case, the sorting effect complements the direct productivity effect in increasing inequality. More generally, the two effects can be offsetting, which raises the possibility that unskilled-biased technical change in developing countries may have raised inequality there.

A key conclusion that emerges from this analysis is that skill biased technical change has a richer set of channels for altering within-industry inequality than does international trade.

\footnotetext{
${ }^{19}$ Since figure 6 plots $w_{i}(S, L)-L$, for this claim to be rigorous we must know what is happening to the variance of $L$. However, the variance of $L$ conditional on $S$ is just $1-\rho^{2}$. Since this is independent of $S$ and the industry of affiliation, we can ignore the variance of $L$.
} 
Both trade and skill biased technical change affect inequality by altering the sorting rule. However, only skill biased technical change has direct effects on within-industry inequality. This is due to the fact that skill biased technical change differentially alters workers' marginal products whereas trade alters all workers' marginal products by the same proportion. Our observation thus offers a deep insight into relative channels for the trade-and-wages debate.

\section{Conclusions}

We examined the implications of worker sorting for the patterns of domestic production and international trade as well as for the demand for protection, income distribution and economic development. Borrowing from Heckman and Sedlacek (1985), our model featured heterogeneous workers who differ in two dimensions e.g., problem solving and communication skills.

We started off by showing that two-skill heterogeneity leads to much richer predictions for production, earnings, and inequality than does the one-skill heterogeneity of, say, Leamer (1999). We then described how higher moments of the bivariate distribution of skills are interesting predictors of trade between rich countries. For example, 'have and have-not' economies such as the United States with its high $\rho$ will export $S$-intensive goods to Sweden and import $L$-intensive goods from Sweden. For another example, economies with high levels of endowment inequality will export goods that intensively use either $S$ or $L$, but not both. We used this to explain U.S. dominance in industries such as film and information technologies and to explain German dominance in machinery and other 'O-Ring' reliable goods involving long chains of production. 
A key feature of our model is that it yields sharp and easily characterized predictions about international patterns of production and trade, even in the case of many goods. In the Heckscher-Ohlin model these predictions are sharp and easily characterized only in the 2-good, 2-factor case. The Heckscher-Ohlin predictions fall flat in all other cases. ${ }^{20}$ In the Specific Factors model the patterns of production and trade depend on impossibly detailed supply elasticities (Jones and Neary, 1984, page 24). These elasticities in turn depend on the cross-industry distribution of industry-specific factors, a distribution that is exogenous and for which little intuition is available. Thus, our model provides a major improvement in our ability to concisely and intuitively predict international patterns of production and trade.

Our model offers an alternative explanation for the demand for protection. The HeckscherOhlin model predicts factor-based lobbying, which has proved useful for understanding broad trade policy debates between labour and capital e.g., Rogowski (1989) and O'Rourke and Williamson (1999). The Specific Factors model predicts industry-based lobbying, which is useful for understanding short-run lobbying by industries with clearly identifiable and exogenous specific factors e.g., mining. Our model predicts both industry- and factor-based lobbying and emphasizes the tension within an industry between those who are endogenously immobile (demanders of industry-based protection) and those who are endogenously mobile (demanders of factor-based protection). Our analysis offers an empirically implementable framework for thinking about the sources of worker immobility or specificity, something the Specific Factors model does not and cannot offer.

\footnotetext{
${ }^{20}(i)$ In the even model with many goods and factors, predictions depend on the complex inverse of the technology matrix and so have no intuitive appeal. (ii) With more goods than factors the predictions are indeterminate. (iii) With more factors than goods the model is simply not interesting.
} 
The model presented offers two additional insights. It explains how a country with a backward technology can survive international competition and how this leads to low earnings. Also, the model has rich predictions about the effects of trade and skill-biased technical change on income distribution. Future research suggested by the model includes (1) empirical work on differences in inequality across industries, (2) empirical work on the role of specificity for lobbying behaviour, and (3) the role new technologies play in enabling multinationals to unbundle worker skills and thus locate design and production in different countries. 


\section{Appendix}

\section{A. Notation}

Define

$$
S^{*} \equiv \frac{S-\mu}{\sigma}, \quad S_{i}^{*} \equiv \frac{S_{i}-\mu}{\sigma}, \quad \text { and } L^{*} \equiv \frac{L-0}{\sigma_{L}} .
$$

Let $\phi_{S L}\left(S^{*}, L^{*}\right)$ be the standard normal bivariate density function for $\left(S^{*}, L^{*}\right)$. Let $\Phi\left(S^{*}\right)$ be the univariate standard normal cumulative distribution function and let $\phi\left(S^{*}\right)$ be the corresponding density. Let

$$
\phi_{S L}\left(S^{*}, L^{*} \mid a<S^{*}<b\right)=\frac{\phi_{S L}\left(S^{*}, L^{*}\right)}{\Phi(b)-\Phi(a)}
$$

be the truncated bivariate normal density. For any function $g\left(S^{*}, L^{*}\right)$, denote its conditional expectation by

$$
\mathbf{E}\left[g\left(S^{*}, L^{*}\right) \mid a<S^{*}<b\right] \equiv \int_{a}^{b} \int_{-\infty}^{\infty} g\left(S^{*}, L^{*}\right) \phi_{S L}\left(S^{*}, L^{*} \mid a<S^{*}<b\right) d L^{*} d S^{*}
$$

and its conditional variance by

$$
\begin{aligned}
& \mathbf{V}\left[g\left(S^{*}, L^{*}\right) \mid a<S^{*}<b\right] \\
\equiv & \int_{a}^{b} \int_{-\infty}^{\infty}\left\{g\left(S^{*}, L^{*}\right)-\mathbf{E}\left[g\left(S^{*}, L^{*}\right) \mid a<S^{*}<b\right]\right\}^{2} \phi_{S L}\left(S^{*}, L^{*} \mid a<S^{*}<b\right) d L^{*} d S^{*} .
\end{aligned}
$$

When $a=S_{i-1}^{*}$ and $b=S_{i}^{*}$ we adopt the simpler notation:

$$
\begin{aligned}
\mathbf{E}\left(g\left(S^{*}, L^{*}\right) \mid i\right) & =\mathbf{E}\left[g\left(S^{*}, L^{*}\right) \mid S_{i-1}^{*}<S^{*}<S_{i}^{*}\right] \\
\mathbf{V}\left(g\left(S^{*}, L^{*}\right) \mid i\right) & =\mathbf{V}\left[g\left(S^{*}, L^{*}\right) \mid S_{i-1}^{*}<S^{*}<S_{i}^{*}\right] .
\end{aligned}
$$

For later reference define

$$
\alpha_{i} \equiv \beta_{i} \sigma+\rho \sigma_{L}
$$

This completes the discussion of notation. We turn next to moments of $\phi_{S L}\left(S^{*}, L^{*} \mid a<\right.$ $\left.S^{*}<b\right)$.

\section{B. Moments of the Truncated Bivariate Normal Distribution}

The moment generating function of the truncated normal bivariate distribution is

$$
\begin{aligned}
& M(u, t) \\
& \equiv \mathbf{E}[\exp (u S+t L) \mid a<(S-\mu) / \sigma<b] \\
& =\exp \left[u \mu+\frac{1}{2}\left(u^{2} \sigma^{2}+t^{2} \sigma_{L}^{2}+2 u t \rho \sigma \sigma_{L}\right)\right]\left[\frac{\Phi\left(b-u \sigma-t \rho \sigma_{L}\right)-\Phi\left(a-u \sigma-t \rho \sigma_{L}\right)}{\Phi(b)-\Phi(a)}\right] .
\end{aligned}
$$


This is useful because as is shown in any introductory statistics textbook, $\mathbf{E}\left[S^{n} L^{m} \mid a<(S-\mu) / \sigma<b\right]$ is given by $d^{n+m} M / d u^{n} d t^{m}$ evaluated at $(u, t)=(0,0)$. Plugging $S^{*}=(S-\mu) / \sigma$ into $d M(0,0) / d u$ yields

$$
\mathbf{E}\left(S^{*} \mid a<S^{*}<b\right)=-\frac{\phi(b)-\phi(a)}{\Phi(b)-\Phi(a)}
$$

One can likewise derive

$$
\begin{gathered}
\mathbf{V}\left(S^{*} \mid a<S^{*}<b\right)=1-\frac{b \phi(b)-a \phi(a)}{\Phi(b)-\Phi(a)}-\left\{\mathbf{E}\left(S^{*} \mid a<S^{*}<b\right)\right\}^{2} \\
\mathbf{E}\left(L \mid a<S^{*}<b\right)=\rho \sigma_{L} \mathbf{E}\left(S^{*} \mid a<S^{*}<b\right) .
\end{gathered}
$$

Since $w_{i}(S, L)=p_{i}+\beta_{i} S+L=p_{i}+\beta_{i} \mu+\beta_{i} \sigma S^{*}+L$, equation (21) and (23) imply

$$
\mathbf{E}\left(w_{i}(S, L) \mid i\right)=p_{i}+\beta_{i} \mu_{S}+\alpha_{i} \mathbf{E}\left(S^{*} \mid i\right) .
$$

$d^{2} M / d u^{2}, d^{2} M / d t^{2}$, and $d^{2} M / d u d t$ evaluated at $(0,0)$ yield

$$
\begin{gathered}
\mathbf{E}\left(S^{2} \mid i\right)=\left[\mu+\sigma E\left(S^{*} \mid i\right)\right]^{2}+\sigma^{2} \mathbf{V}\left(S^{*} \mid i\right) \\
\mathbf{E}\left(L^{2} \mid i\right)=\left[\rho \sigma_{L} \mathbf{E}\left(S^{*} \mid i\right)\right]^{2}+\sigma_{L}^{2} \rho^{2} \mathbf{V}\left(S^{*} \mid i\right)+\sigma_{L}^{2}\left(1-\rho^{2}\right) \\
\mathbf{E}(L S \mid i)=\left[\rho \sigma_{L} \mathbf{E}\left(S^{*} \mid i\right)\right]\left[\mu+\sigma \mathbf{E}\left(S^{*} \mid i\right)\right]+\rho \sigma_{L} \sigma \mathbf{V}\left(S^{*} \mid i\right)
\end{gathered}
$$

from which it follows that

$$
\mathbf{V}\left(w_{i}(S, L) \mid i\right)=\sigma_{L}^{2}\left(1-\rho^{2}\right)+\alpha_{i}^{2} \mathbf{V}\left(S^{*} \mid i\right)
$$

\section{Output}

Applying the equation (16) change of variable to equation (6) yields

$$
Y_{i}=A_{i} \int_{S_{i-1}^{*}}^{S_{i}^{*}} \int_{-\infty}^{\infty} \exp \left(\beta_{i} S+L\right) \phi_{S L}\left(S^{*}, L^{*}\right) d L^{*} d S^{*}
$$

From equation (17) with $b=S_{i}^{*}$ and $a=S_{i-1}^{*}$ this can be written as

$$
Y_{i}=A_{i}\left[\Phi\left(S_{i}^{*}\right)-\Phi\left(S_{i-1}^{*}\right)\right] \mathbf{E}\left[\exp \left(\beta_{i} S+L\right) \mid S_{i-1}^{*}<S^{*}<S_{i}^{*}\right] .
$$

From this and equation $(20)$ evaluated at $(u, t)=\left(\beta_{i}, 1\right)$,

$$
\ln Y_{i}=\ln A_{i}+\beta_{i} \mu+\frac{1}{2}\left(\beta_{i}^{2} \sigma^{2}+\sigma_{L}^{2}+2 \beta_{i} \rho \sigma \sigma_{L}\right)+\ln \left[\Phi\left(S_{i}^{*}-\alpha_{i}\right)-\Phi\left(S_{i-1}^{*}-\alpha_{i}\right)\right] .
$$

We will use this expression repeatedly in what follows. 


\section{Proof of Equation (11)}

Differentiation of equation (27) yields

$$
\frac{d \ln Y_{i}}{d \rho}=\beta_{i} \sigma \sigma_{L}-\sigma_{L} \frac{\phi\left(S_{i}^{*}-\alpha_{i}\right)-\phi\left(S_{i-1}^{*}-\alpha_{i}\right)}{\Phi\left(S_{i}^{*}-\alpha_{i}\right)-\Phi\left(S_{i-1}^{*}-\alpha_{i}\right)}
$$

Simplifying using equation (21),

$$
\begin{aligned}
\frac{1}{\sigma_{L}} \frac{d \ln Y_{i}}{d \rho} & =\beta_{i} \sigma+\mathbf{E}\left[S^{*} \mid S_{i-1}^{*}-\alpha_{i}<S^{*}<S_{i}^{*}-\alpha_{i}\right] \\
& =\mathbf{E}\left[S^{*}+\alpha_{i} \mid S_{i-1}^{*}-\alpha_{i}<S^{*}<S_{i}^{*}-\alpha_{i}\right]-\rho \sigma_{L}
\end{aligned}
$$

where the second equality comes from equation (19) i.e. $\beta_{i} \sigma=\alpha_{i}-\rho \sigma_{L}$. Equation (11) follows from the definition of $\mathbf{E}_{i}\left(\alpha_{i}\right)$ in lemma 1.

\section{E. Proof of Theorem 2}

Let $Y_{i}^{W}$ be world output of good $i$. By market clearing it equals world consumption of good $i$. Let $C_{i}$ be home consumption of good $i$. By homotheticity, $C_{i} / Y_{i}^{W}$ equals the home country's share of world income and so is the same for all $i$. By theorem $1, Y_{i} / Y_{i}^{W}$ is increasing in $i$. Hence $\left(Y_{i}-C_{i}\right) / Y_{i}^{W}$ is increasing in $i$. Let $T_{i} \equiv Y_{i}-C_{i}$ be net exports. By balanced trade, at least one good is exported and at least one good is imported. Since $T_{i} / Y_{i}^{W}$ is increasing in $i$, if $T_{i}>0$ then $T_{i+j}>0$ for all $j>0$ and if $T_{i}<0$ then $T_{i-j}<0$ for all $j>0$. It follows that there is a unique $i_{\rho}<n$ such that $T_{i}>0$ for $i>i_{\rho}, T_{i_{\rho}} \leq 0$, and $T_{i}<0$ for $i<i_{\rho}$.

\section{F. Proof of Equation (13)}

We begin with a preliminary result. Any variance can be rewritten as the expectation of the square minus the square of the expectation. Thus, $\mathbf{V}\left(S_{i}^{*} \mid a<S^{*}<b\right)=\mathbf{E}\left(S^{* 2} \mid a<S^{*}<b\right)-$ $\left[\mathbf{E}\left(S^{*} \mid a<S^{*}<b\right)\right]^{2}$. Plugging this into equation (22) yields

$$
-\frac{b \phi(b)-a \phi(a)}{\Phi(b)-\Phi(a)}=\mathbf{E}\left(S^{* 2} \mid a<S^{*}<b\right)-1 .
$$

We next provide an expression for $d \ln Y_{i} / d \ln \sigma$. Differentiation of equation (27) with respect to $\sigma$ yields

$$
\frac{d \ln Y_{i}}{d \sigma}=\beta_{i}^{2} \sigma+\beta_{i} \rho \sigma_{L}-\frac{1}{\sigma} \frac{\left(S_{i}^{*}+\beta_{i} \sigma\right) \phi\left(S_{i}^{*}-\alpha_{i}\right)-\left(S_{i-1}^{*}+\beta_{i} \sigma\right) \phi\left(S_{i-1}^{*}-\alpha_{i}\right)}{\Phi\left(S_{i}^{*}-\alpha_{i}\right)-\Phi\left(S_{i-1}^{*}-\alpha_{i}\right)} .
$$

Substituting $S_{i}^{*}+\beta_{i} \sigma=\left(S_{i}^{*}-\alpha_{i}\right)+\left(\alpha_{i}+\beta_{i} \sigma\right), d \sigma=\sigma d \ln \sigma$, equation (21) and equation 
(28) into equation (29) yields

$$
\begin{aligned}
\frac{d \ln Y_{i}}{d \ln \sigma}= & \beta_{i}^{2} \sigma^{2}+\beta_{i} \sigma \rho \sigma_{L}-1+\mathbf{E}\left(S^{* 2} \mid S_{i-1}^{*}-\alpha_{i}<S^{*}<S_{i}^{*}-\alpha_{i}\right) \\
& +\left(\alpha_{i}+\beta_{i} \sigma\right) \mathbf{E}\left(S^{*} \mid S_{i-1}^{*}-\alpha_{i}<S^{*}<S_{i}^{*}-\alpha_{i}\right)
\end{aligned}
$$

We next provide an expression for $d \ln Y_{i} / d \ln \sigma_{L}$. Differentiation of equation (27) with respect to $\sigma_{L}$ yields

$$
\frac{d \ln Y_{i}}{d \sigma_{L}}=\sigma_{L}+\beta_{i} \sigma \rho-\rho \frac{\phi\left(S_{i}^{*}-\alpha_{i}\right)-\phi\left(S_{i-1}^{*}-\alpha_{i}\right)}{\Phi\left(S_{i}^{*}-\alpha_{i}\right)-\Phi\left(S_{i-1}^{*}-\alpha_{i}\right)} .
$$

From equation (21) and $d \sigma_{L}=\sigma_{L} d \ln \sigma_{L}$, this simplifies to

$$
\frac{d \ln Y_{i}}{d \ln \sigma_{L}}=\sigma_{L}^{2}+\beta_{i} \sigma \rho \sigma_{L}+\rho \sigma_{L} \mathbf{E}\left(S^{*} \mid S_{i-1}^{*}-\alpha_{i}<S^{*}<S_{i}^{*}-\alpha_{i}\right)
$$

Finally, from the definition of $\gamma$, an increase in $\gamma$ leads to proportional increases in $\sigma$ and $\sigma_{L}$ : $d \ln \sigma / d \ln \gamma=d \ln \sigma_{L} / d \ln \gamma=1$. Thus, from equations (30)-(31) and $\alpha_{i}^{2} \equiv \beta_{i}^{2} \sigma^{2}+\rho^{2} \sigma_{L}^{2}+$ $2 \beta_{i} \sigma \rho \sigma_{L}$

$$
\begin{aligned}
\frac{d \ln Y_{i}}{d \ln \gamma}= & \frac{d \ln Y_{i}}{d \ln \sigma}+\frac{d \ln Y_{i}}{d \ln \sigma_{L}} \\
= & \sigma_{L}^{2}\left(1-\rho^{2}\right)-1+\alpha_{i}^{2}+2 \alpha_{i} \mathbf{E}\left(S^{*} \mid S_{i-1}^{*}-\alpha_{i}<S^{*}<S_{i}^{*}-\alpha_{i}\right) \\
& +\mathbf{E}\left(S^{* 2} \mid S_{i-1}^{*}-\alpha_{i}<S^{*}<S_{i}^{*}-\alpha_{i}\right) \\
= & \mathbf{E}\left[\left(S^{*}+\alpha_{i}\right)^{2} \mid S_{i-1}^{*}-\alpha_{i}<S^{*}<S_{i}^{*}-\alpha_{i}\right]+\sigma_{L}^{2}\left(1-\rho^{2}\right)-1 .
\end{aligned}
$$

\section{G. Proof of Theorem 4}

Let $Y_{i}^{W}$ be world output of good $i$. By market clearing it equals world consumption of good $i$. Let $C_{i}$ be home consumption of good i. By homotheticity, $C_{i} / Y_{i}^{W}$ equals the home country's share of world income and so is the same for all $i$. By theorem $3, Y_{i} / Y_{i}^{W}$ is increasing in $i$ for $i>i_{\gamma}$ and decreasing in $i$ for $i \leq i_{\gamma}$. Let $T_{i} \equiv Y_{i}-C_{i}$ be net exports. Then $T_{i} / Y_{i}^{W}$ is increasing in $i$ for $i>i_{\gamma}$ and decreasing in $i$ for $i \leq i_{\gamma}$. It follows that if $i_{\gamma}$ were exported $\left(T_{i_{\gamma}}>0\right)$ then all goods are exported. By balanced trade at least one industry must be imported. Hence $i_{\gamma}$ is imported.

Suppose some good $i>i_{\gamma}$ is exported. Then since $T_{i} / Y_{i}^{W}$ is increasing in $i$ there must be a good $\bar{i}_{\gamma}$ such that $T_{i}<0$ for $i=i_{\gamma}, \ldots, \bar{i}_{\gamma}-2, T_{\bar{i}_{\gamma}-1} \leq 0$, and $T_{i}>0$ for $i=\bar{i}_{\gamma}, \ldots, n$. Similarly, suppose that some good $i<i_{\gamma}$ is exported. Then since $T_{i} / Y_{i}^{W}$ is decreasing in $i$ there must be a good $\underline{i}_{\gamma}$ such that $T_{i}>0$ for $i=1, \ldots, \underline{i}_{\gamma}-1, T_{\underline{i}_{\gamma}} \geq 0$, and $T_{i}<0$ for $i=\underline{i}_{\gamma}+1, \ldots, i_{\gamma}$. It remains to show that some good $i>i_{\gamma}$ is exported and some good $i<i_{\gamma}$ is exported.

Let $\delta$ be the home country's income share. By homotheticity, $C_{i}=\delta Y_{i}^{W}$. Since $i_{\gamma}<n$ by assumption, theorem 3 implies $Y_{n}>\delta Y_{n}^{w}$. Hence $T_{n} \equiv Y_{n}-C_{n}>0$ i.e., some good $i>i_{\gamma}$ is exported. Since $i_{\gamma}>1$ by assumption, theorem 3 implies $Y_{1}>\delta Y_{1}^{w}$. Hence 
$T_{1} \equiv Y_{1}-C_{1}>0$ i.e., some good $i<i_{\gamma}$ is exported.

\section{H. Proof of Equation (14)}

From equation (27),

$$
\frac{d \ln Y_{i}}{d \mu}=-\frac{1}{\sigma} \frac{\phi\left(S_{i}^{*}-\alpha_{i}\right)-\phi\left(S_{i-1}^{*}-\alpha_{i}\right)}{\Phi\left(S_{i}^{*}-\alpha_{i}\right)-\Phi\left(S_{i-1}^{*}-\alpha_{i}\right)}+\beta_{i}
$$

Simplifying using equation (21) and substituting in $\beta_{i} \sigma=\alpha_{i}-\rho \sigma_{L}$ from equation (19) yields

$$
\sigma \frac{d \ln Y_{i}}{d \mu}=\mathbf{E}\left[S^{*}+\alpha_{i} \mid S_{i-1}^{*}-\alpha_{i}<S^{*}<S_{i}^{*}-\alpha_{i}\right]-\rho \sigma_{L} .
$$

Equation (14) follows from the definition of $\mathbf{E}_{i}\left(\alpha_{i}\right)$ in lemma 1.

\section{Proof of Theorem 6}

By comparison of equations (11) and (14), the proof is identical to the proof of theorem 2.

\section{J. Proof of Theorem 7}

The derivative of output in industry $i$ with respect to $\ln A_{i}$ is:

$$
\frac{d \ln Y_{i}}{d \ln A_{i}}=1+\frac{1}{\sigma} \frac{\frac{1}{\beta_{i+1}-\beta_{i}} \phi\left(S_{i}^{*}-\alpha_{i}\right)+\frac{1}{\beta_{i}-\beta_{i-1}} \phi\left(S_{i-1}^{*}-\alpha_{i}\right)}{\Phi\left(S_{i}^{*}-\alpha_{i}\right)-\Phi\left(S_{i-1}^{*}-\alpha_{i}\right)}>0 .
$$

The derivatives of output in industries $i-1$ and $i+1$ with respect to $p_{i}$ are:

$$
\begin{aligned}
& \frac{d \ln Y_{i-1}}{d \ln A_{i}}=-\frac{1}{\sigma} \frac{\frac{1}{\beta_{i}-\beta_{i-1}} \phi\left(S_{i-1}^{*}-\alpha_{i-1}\right)}{\Phi\left(S_{i-1}^{*}-\alpha_{i-1}\right)-\Phi\left(S_{i-2}^{*}-\alpha_{i-1}\right)}<0, \\
& \frac{d \ln Y_{i+1}}{d \ln A_{i}}=-\frac{1}{\sigma} \frac{\frac{1}{\beta_{i+1}-\beta_{i}} \phi\left(S_{i}^{*}-\alpha_{i+1}\right)}{\Phi\left(S_{i+1}^{*}-\alpha_{i+1}\right)-\Phi\left(S_{i}^{*}-\alpha_{i+1}\right)}<0 .
\end{aligned}
$$

To prove part 2 of the theorem let $Y_{i}^{W}$ be world output of good $i$. By market clearing it equals world consumption of good $i$. Let $C_{i}$ be home consumption of good $i$. By homotheticity, $C_{i}=\delta Y_{i}^{W}$ for all $i$ where $\delta$ is the home country's share of world income. By part 1 , $Y_{i}>\delta Y_{i}^{W}, Y_{i-1}<\delta Y_{i-1}^{W}$, and $Y_{i+1}<\delta Y_{i+1}^{W}$. Hence $T_{i} \equiv Y_{i}-C_{i}>0, T_{i-1}<0$ and $T_{i+1}>0$. Finally, $Y_{j}=\delta Y_{j}^{W}$ for $j<i-1$ and $j>i+1$ so that $T_{j}=0$. 


\section{K. Proof of Theorem 8}

From equation (26) with $\mathbf{V}\left(S^{*} \mid i\right)$ written out in full as $\mathbf{V}\left(S^{*} \mid S_{i-1}^{*}<S^{*}<S_{i}^{*}\right)$, the derivative of the variance of $\log$ earnings in industry $i$ with respect to $q_{i}$ is

$$
\frac{d \mathbf{V}\left(w_{i}(S, L) \mid i\right)}{d q_{i}}=\frac{\alpha_{i}^{2}}{\sigma} \frac{d \mathbf{V}\left(S^{*} \mid S_{i-1}^{*}<S^{*}<S_{i}^{*}\right)}{d S_{i}^{*}} \frac{d S_{i}^{*}}{d q_{i}}+\frac{\alpha_{i}^{2}}{\sigma} \frac{d \mathbf{V}\left(S^{*} \mid S_{i-1}^{*}<S^{*}<S_{i}^{*}\right)}{d S_{i-1}^{*}} \frac{d S_{i-1}^{*}}{d q_{i}} .
$$

From equations (2) and (5), $d S_{i}^{*} / d q_{i}=1 /\left(\beta_{i+1}-\beta_{i}\right)$ and $d S_{i-1}^{*} / d q_{i}=1 /\left(\beta_{i}-\beta_{i-1}\right)$ from which equation (15) follows. Heckman and Sedlacek (1985, proposition 1) states that $d \mathbf{V}\left(S^{*} \mid i\right) / d S_{i}^{*}>0$ and $d \mathbf{V}\left(S^{*} \mid i\right) / d S_{i-1}^{*}<0$ if $S^{*}$ is distributed according to a log concave distribution. The normal distribution is log concave. Applying this to equation (15) yields $d \mathbf{V}(w(S, L) \mid i) / d q_{i}>0$.

The derivatives of the within-industry variance of log earnings in industries $i-1$ and $i+1$ with respect to $q_{i}$ are given by:

$$
\begin{gathered}
\frac{d \mathbf{V}\left(w_{i}(S, L) \mid i+1\right)}{d q_{i}}=\frac{\alpha_{i+1}^{2}}{\sigma\left(\beta_{i+1}-\beta_{i}\right)} \frac{d \mathbf{V}\left(S^{*} \mid i+1\right)}{d S_{i}^{*}}<0, \\
\frac{d \mathbf{V}\left(w_{i}(S, L) \mid i-1\right)}{d q_{i}}=-\frac{\alpha_{i-1}^{2}}{\sigma\left(\beta_{i}-\beta_{i-1}\right)} \frac{d \mathbf{V}\left(S^{*} \mid i-1\right)}{d S_{i-1}^{*}}<0 .
\end{gathered}
$$




\section{References}

Atkinson, Anthony B. and Francois Bourguignon, "The Comparison of MultiDimensioned Distributions of Economic Status," Review of Economic Studies, April 1982, $49(2), 183-201$.

Bailey, Martin Neil and Hans Gersbach, "Efficiency in Manufacturing and the Need for Global Competition," Brookings Papers on Economic Activity, Microeconomics, 1995, pp. $307-347$.

Bartel, Ann P. and Nachum Sicherman, "Technological Change and Wages: An Interindustry Analaysis," Journal of Politcal Economy, April 1999, 107 (2), 285-325.

Beaulieu, Eugene, "Factor Industry Cleavages in Trade Policy: An Empirical Analysis of the Stolper-Samuelson Theorem," Economics and Politics, July 2002, 14 (2), 99-131.

Björklund, Anders and Markus Jänti, "Intergenerational Income Mobility in Sweden Compared to the United States," American Economic Review, December 1997, 87 (5), 1009-1018.

Blanden, Jo, "International Evidence on Intergenerational Mobility," Technical Report, Centre for Economic Performance, London School of Economics, April 2004.

Dixit, Avinash and Victor Norman, Theory of international trade : a dual, general equilibrium approach, Welwyn, England: J. Nisbet., 1980.

Goldberg, Pinelopi and Giovanni Maggi, "Protection for Sale: An Empirical Investigation," American Economic Review, December 1999, 89 (5), 1135-55.

Grossman, Gene M., "Partially Mobile Capital: A General Approach to Two-Sector Trade Theory," Journal of International Economics, August 1983, 15 (1-2), 1-17.

_ , "Imperfect Labor Contracts and International Trade," Journal of Political Economy, February 2004, 112 (1), 209-239.

- and Giovanni Maggi, "Diversity and Trade," American Economic Review, December 2000, $90(5), 1255-1275$.

Heckman, James and Bo Honoré, "The Empirical Content of the Roy Model," Econometrica, September 1990, 58 (5), 1121-1149.

_ and Guilherme Sedlacek, "Heterogeneity, Aggregation, and Market Wage Functions: An Empirical Model of Self-Selection in the Labour Market," Journal of Political Economy, December 1985, 93 (6), 1077-1116.

- and Jose Scheinkman, "The Importance of Bundling in a Gorman-Lancaster Model of Earnings," Review of Economic Studies, April 1987, 54 (2), 243-255.

Jacobson, Louis S., Robert J. LaLonde, and Daniel G. Sullivan, "Earnings Losses of Displaced Workers," American Economic Review, September 1993, 83 (4), 685-709. 
Jones, Ronald W. and J. Peter Neary, "The Positive Theory of International Trade," in Peter B. Kenen Ronald W. Jones, ed., Handbook of International Economics, Amsterdam and New York: North Holland, 1984.

Leamer, Edward E., "Welfare Computations and the Optimal Staging of Tariff Reductions in Models with Adjustment Costs," Journal of International Economics, February 1980, $10(1), 21-36$.

_ , "Effort, Wages, and the International Division of Labour," Journal of Political Economy, December 1999, $10^{r}$ (6), 1127-1162.

Magee, Stephen P., William A. Brook, and Leslie Young, Black hole tariffs and endogenous policy theory: Political economy in general equilibrium, Cambridge: Cambridge University Press, 1989.

Mayer, Wolfgang, "Short-Run and Long-Run Equilibrium for a Small Open Economy," Journal of Political Economy, September-October 1974, 82 (5), 955-967.

Melitz, Marc J., "The Impact of Trade on Intra-industry Reallocations and Aggregate Industry Productivity," Econometrica, November 2003, 71 (6), 1695-1725.

Murnane, Richard J. and Frank Levy, Teaching the new basic skills: Principles for educating children to thrive in a changing economy, New York: Simon and Schuster, Free Press, Martin Kessler Books, 1996.

Mussa, Michael, "Tariffs and the Distribution of Income: The Importance of Factor Specificity, Substitutability, and Intensity in the Short and Long Run," Journal of Political Economy, November-December 1974, 82 (6), 1191-1203.

O'Rourke, Kevin H. and Jeffrey G. Williamson, Globalization and history: The evolution of a nineteenth-century Atlantic economy, Cambridge: MIT Press, 1999.

Osterman, Paul, "Skill, Training, and Work Organization in American Establishments," Industrial Relations, April 1995, 34 (2), 125-146.

Pack, Howard, "Productivity and Technical Choice: Applications to the Textile Industry," Journal of Development Economics, September-October 1984, 16 (1-2), 153-176.

Rogowski, Ronald, Commerce and coalitions: How trade affects domestic political alignments, Princeton: Princeton University Press, 1989.

Rosen, Sherwin, "Learning and Experience in the Labour Market," Journal of Human Resources, Summer 1972, 7 (3), 327-341.

_ , "Hedonic Prices and Implicit Markets: Product Differentiation in Pure Competition," Journal of Political Economy, January-February 1974, 82 (1), 34-55.

_, "Substitution and Division of Labour," Economica, August 1978, 45 (179), 235-250. 
_ , "The Economics of Superstars," American Economic Review, December 1981, 71 (5), 843-858.

_ , "A Note on Aggregation of Skills and Labor Quality [Linear Synthesis of Skill Distribution]," Journal of Human Resources, Summer 1983, 18 (3), 425-431.

Roy, Andrew D., "The Distribution of Earnings and of Individual Output," Economic Journal, September 1950, 60 (239), 489-505.

_ , "Some Thoughts on the Distribution of Earnings," Oxford Economic Papers, June 1951, 3 (2), 135-146.

Ruffin, Roy J., "Quasi-Specific Factors: Worker Comparative Advantage in the TwoSector Production Model," Technical Report February 1999.

Sattinger, Michael, "Comparative Advantage and the Distributions of Earnings and Abilities," Econometrica, May 1975, 43 (3), 455-468.

_, Capital and the Distribution of Labor Earnings, Amsterdam: North-Holland, 1980.

Slaughter, Matthew J. and Kenneth F. Scheve, "What Determines Individual TradePolicy Preferences?," Journal of International Economics, August 2001, 54 (2), 267-292.

Solon, Gary, "Cross-Country Differences in Intergenerational Earnings Mobility," Journal of Economic Perspectives, Summer 2002, 16 (3), 59-66.

Teulings, Coen N., "The Wage Distribution in a Model of the Assignment of Skills to Jobs," Journal of Political Economy, April 1995, 103 (2), 280-315.

Trefler, Daniel, "Trade Liberalization and the Theory of Endogenous Protection: An Econometric Study of U.S. Import Policy," Journal of Political Economy, February 1993, 101 (1), 138-160.

_ , "Looking Backwards: How Childhood Experiences Impact a Nations's Wealth," February 2004. Mimeo, University of Toronto.

Welch, Finis, "Linear Synthesis of Skill Distribution," Journal of Human Resources, Summer 1969, 4 (3), 311-327.

Willis, Robert J. and Sherwin Rosen, "Education and Self-Selection," Journal of Political Economy, October 1979, 87 (5), S7-S36. 